\title{
Combining asteroid models derived by lightcurve inversion with asteroidal occultation silhouettes
}

\author{
Josef Ďurech $^{\mathrm{a}, *}$, Mikko Kaasalainen ${ }^{\mathrm{b}}$, David Herald ${ }^{\mathrm{c}}$, David Dunham ${ }^{\mathrm{d}}$, Brad Timerson ${ }^{\mathrm{e}}$, Josef Hanuš ${ }^{\mathrm{a}}$, Eric Frappa ${ }^{\mathrm{f}}$, \\ John Talbot ${ }^{\mathrm{g}}$, Tsutomu Hayamizu ${ }^{\mathrm{h}}$, Brian D. Warner ${ }^{\mathrm{i}}$, Frederick Pilcher ${ }^{\mathrm{j}}$, Adrián Galád ${ }^{\mathrm{k}, \mathrm{l}}$ \\ ${ }^{a}$ Astronomical Institute, Faculty of Mathematics and Physics, Charles University in Prague, V Holešovičkách 2, CZ-18000 Prague, Czech \\ Republic \\ ${ }^{b}$ Department of Mathematics, Tampere University of Technology, P.O. Box 553, 33101 Tampere, Finland \\ ${ }^{c} 3$ Lupin Pl, Murrumbateman, NSW, Australia \\ ${ }^{d}$ International Occultation Timing Association (IOTA) and KinetX, Inc., 7913 Kara Ct., Greenbelt, MD 20770, USA \\ ${ }^{e}$ International Occultation Timing Association (IOTA), 623 Bell Rd., Newark, NY, USA \\ ${ }^{f} 1$ bis cours Jovin Bouchard 42000 Saint-Etienne, France \\ ${ }^{g}$ Occultation Section, Royal Astronomical Society of New Zealand, P.O. Box 3181, Wellington, New Zealand \\ ${ }^{h}$ Japan Occultation Information Network (JOIN), Sendai Space Hall, 2133-6 Nagatoshi, Kagoshima pref, Japan \\ ${ }^{i}$ Palmer Divide Observatory, 17955 Bakers Farm Rd., Colorado Springs, CO 80908, USA \\ ${ }^{j} 4438$ Organ Mesa Loop, Las Cruces, NM 88011, USA \\ ${ }^{k}$ Modra Observatory, FMFI Comenius University, 84248 Bratislava, Slovakia \\ ${ }^{l}$ Ondřejov Observatory, $A V \breve{C} R, 25165$ Ondřejov, Czech Republic
}

\begin{abstract}
Asteroid sizes can be directly measured by observing occultations of stars by asteroids. When there are enough observations across the path of the shadow, the asteroid's projected silhouette can be reconstructed. Asteroid shape models derived from photometry by the lightcurve inversion method enable us to predict the orientation of an asteroid for the time of occultation. By scaling the shape model to fit the occultation chords, we can determine the asteroid 'size with a relative accuracy of typically $\sim 10 \%$. We combine shape and spin state models of 44 asteroids (14 of them are new or updated models) with the available occultation data to derive asteroid effective diameters. In many cases, occultations allow us to reject one of two possible pole solutions that were derived from photometry. We show that by combining results obtained from lightcurve inversion with occultation timings, we can obtain unique physical models of 'asteroids.
\end{abstract}

\section{Keywords: Asteroids, Occultations, Photometry}

\section{Introduction}

Occultations of stars by asteroids are relatively fre'quent events systematically observed mainly by amateur astronomers. The projected silhouette of the occulting asteroid can be derived from accurate timings of the disappearance and reappearance of the star measured by several observers placed across the path of the shadow. Apart from a precise measurement of the relative astrometric position of the star and the asteroid at the time of the event, the main scientific value of a well observed occultation is the direct and relatively accurate measurement of the asteroid's dimension. Asteroid sizes derived from occultations can serve as an independent check of values obtained by, e.g., thermal radiometric observations. From the diameter and the absolute magnitude of an asteroid, we can derive its geometric albedo (Shevchenko and Tedesco, 2006).

\footnotetext{
* Corresponding author

Email address: durech@sirrah.troja.mff.cuni.cz (Josef Ďurech)
}

The number of observed occultations has increased dramatically with the availability of high-accuracy star catalogues based on the Hipparcos data (Dunham et al., 2002). Nowadays, occultations can be predicted well in advance with sufficient accuracy. A further dramatic increase of the number of accurate predictions will come with the stellar catalogue based on the astrometric mission Gaia (Tanga and Delbo, 2007).

Over 1700 occultations have been observed so far. The majority of them were observed by less than three observers and they do not provide any reliable silhouette estimation. These occultations can yield only a lower limit of the asteroid size. However, there are several hundred occultation events with a sufficient number of well defined chords that provide enough data to reconstruct more or less accurately the projected silhouette.

Until now, the usual final result of all reduced occultations was an ellipse fitting the projected silhouette and approximating the asteroid's dimensions. In a few cases, the occultation data were processed together with optical lightcurves in order to derive the asteroid's triax- 
ial ellipsoid shape model (Drummond and Cocke, 1989; Dunham et al., 1990; Sato et al., 1993, 2000).

The reconstruction of a $3 \mathrm{D}$ shape model from several occultation $2 \mathrm{D}$ projections is possible in principle but still unrealized in practice due to the lack of data. On the other hand, there are more than one hundred asteroid shape models that have been derived in the past decade by the lightcurve inversion method of Kaasalainen and Torppa (2001) and Kaasalainen et al. (2001). These models are archived in the Database of Asteroid Models from Inversion Techniques (DAMIT) 1 ( (Durech et al., 2010).

The reliability of models derived by the lightcurve inversion technique has been confirmed by their comparison with models obtained by radar or with direct spacecraft imaging and by laboratory experiments (Kaasalainen et al., 2005). Convex models are inevitably only approximations of real shapes and cannot provide us with shape details. However, the derived rotation periods and spin directions have very good agreement with independent results (Kaasalainen et al., 2001). Using the model, the asteroid's orientation can be computed for the epoch of the occultation and the observed projection can be compared with the predicted silhouette of the model. The basic result of such combination of occultation data and shape models is that the models from lightcurve inversion can be calibrated to absolute dimensions of the asteroid (Timerson et al., 2009). Moreover, if we include the occultation profile into the optimization procedure, we can refine the model and reveal shape details that are in principle unobtainable from lightcurves only. Lightcurve inversion provides unique solutions only for convex shapes, so occultations can help in detecting concavities.

For this paper, we have selected more than forty such asteroids, that have lightcurve inversion models in DAMIT and also occultation observations that can be used for scaling the model. We also present ten new or updated models that we also scale using the occultation data. Although some multi-chord occultation data are of sufficient quality to enable us to carry out the full multi-data inversion with fitting not only the size but also the shape to the occultation data, we leave this for a forthcoming paper. We describe the data reduction and optimization process in Sect. 2 and we report our results in Sect. 3 .

\section{Data reduction and optimization}

\subsection{Occultations}

During an occultation, the asteroid's shadow moves on the Earth's surface and observers within the occultation path measure the times of disappearance and reappearance of the occulted star. The negative reports from observers outside of the path put limits on the dimensions of asteroid's cross-section. The duration of a typical event is from seconds to tens of seconds. If the observations are

${ }^{1}$ http://astro.troja.mff.cuni.cz/projects/asteroids3D made visually, the reaction times of individual observers can involve significant systematic errors.

The occultation data we use were taken mainly from the NASA PDS database (Dunham and Herald, 2009) that contains data up to 2008. More recent occultation data were provided directly by the International Occultation Timing Association (IOTA)2, by the Asteroidal Occultation Observers in Europe 3 , by the Occultation Section of the Royal Astronomical Society of New Zealand 4 , and by Japanese observers of asteroidal occultations 5 . The data were processed in the standard way described, for example, by Millis and Elliot (1979) or Wasserman et al. (1979). Here we follow the notation used by Kaasalainen (2003).

Each observed time of disappearance and reappearance defines a point on the limb of the asteroid. We define the fundamental plane that passes through the center of the Earth and is instantaneously perpendicular to the line connecting the star (assuming to be at infinity) and the center of the asteroid. Then the coordinate system $(\xi, \eta)$ on the fundamental plane is defined by two unit vectors

$$
\begin{aligned}
& \hat{\vec{s}}_{\xi}=(-\sin \delta \cos \alpha,-\sin \delta \sin \alpha, \cos \delta), \\
& \hat{\vec{s}}_{\eta}=(\sin \alpha,-\cos \alpha, 0),
\end{aligned}
$$

where $\alpha$ and $\delta$ are the right ascension and declination of the occulted star. For prediction purposes, it is important to use apparent coordinates of the star. However, for our purposes, the difference between the apparent and the mean position can be neglected and we use J2000.0 coordinates.

The geocentric coordinates of an observer are projected onto the fundamental plane

$$
(\xi, \eta)=\left[\hat{\vec{s}}_{\xi} \cdot(\vec{x}+\Delta \vec{v} \Delta t), \hat{\vec{s}}_{\eta} \cdot(\vec{x}+\Delta \vec{v} \Delta t)\right],
$$

where $\vec{x}$ is the observer's position on the Earth in the sidereal equatorial frame, $\vec{x}=$ $(R \cos \varphi \cos \theta, R \cos \varphi \sin \theta, R \sin \varphi)$, where $R$ is the observer's distance from the Earth's center, $\varphi$ is the geocentric latitude and $\theta$ is the local sidereal time, $\Delta \vec{v}$ denotes the differential space velocity $\vec{v}_{\text {Earth }}-\vec{v}_{\text {asteroid }}$ in the equatorial frame $(\Delta \vec{v}$ is assumed to be constant during the occultation), $\Delta t$ is the time of disappearance/reappearance measured from some epoch. If the $\Delta t$ times for individual observations do not differ much (compared to the asteroid's rotation period) the points $(\xi, \eta)$ can be taken as a 'snapshot' of the asteroid's projection at the time $\Delta t$. This approximation is not needed in the analysis but we used it because the asteroids rotated by only a small number of degrees during the observations in most cases. Moreover, as we only scaled

${ }^{2}$ http://www.lunar-occultations.com/iota/iotandx.htm

3 http://www . euraster.net

${ }^{4}$ http://occsec.wellington.net.nz/planet/plnreslt.htm

5 http://uchukan.satsumasendai.jp/data/occult-e/occult-e.html 
the models without actually modifying their shapes, this simplification is fully appropriate.

The assumption of a linear differential space velocity made in Eq. (2) is appropriate if (i) the reference time is set so that $\Delta t \lesssim 10 \mathrm{~min}$, and (ii) all the observations were made from the same region of the world, which means that the individual timings $\Delta t$ do not differ more than $\sim 10$ min. This was fulfilled for all occultations we present in Sect. 3. The maximum relative difference between projections computed according to Eq. (2) and those computed according to a more precise quadratic expression

$$
\begin{aligned}
(\xi, \eta)= & {\left[\hat{\vec{s}}_{\xi} \cdot\left(\vec{x}+\Delta \vec{v} \Delta t+\frac{1}{2} \Delta \dot{\vec{v}}(\Delta t)^{2}\right),\right.} \\
& \left.\hat{\vec{s}}_{\eta} \cdot\left(\vec{x}+\Delta \vec{v} \Delta t+\frac{1}{2} \Delta \dot{\vec{v}}(\Delta t)^{2}\right)\right],
\end{aligned}
$$

is only $\sim 1 \%$, which is well below the accuracy we need.

\subsection{Shape models from lightcurve inversion}

The shape models of the asteroids used in this work were taken from DAMIT or derived from new observations (see Sect. 3). All models were derived by the lightcurve inversion method described in Kaasalainen and Torppa (2001) and Kaasalainen et al. (2001). They are convex polyhedrons (the convexity is the property of almost all DAMIT models, but nonconvex models can be used as well) with triangular facets defined by radius vectors $\vec{r}$ of the surface points. Their orientation in space at any given time can be computed from the ecliptic longitude and latitude $\left(\lambda_{\mathrm{p}}, \beta_{\mathrm{p}}\right)$ of the spin axis direction (the $z$ axis in the asteroid Cartesian coordinate frame), the sidereal rotation period $P$ and the initial rotation angle $\varphi_{0}$ given for some epoch. The detailed description of the rotation matrices of the transformation from the asteroid body frame to the ecliptic frame is given by Durech et al. (2010). Thus, for a given time $\Delta t$ of an occultation, we can project an asteroid onto the fundamental plane. The radius vectors $\vec{r}$ are transformed to the equatorial coordinate system $\vec{r}_{\text {eq }}$. Then the projected coordinates $\left(\xi_{\bmod }, \eta_{\bmod }\right)$ of the polyhedron vertices are

$$
\left(\xi_{\mathrm{mod}}, \eta_{\mathrm{mod}}\right)=\left(\hat{\vec{s}}_{\xi} \cdot \vec{r}_{\mathrm{eq}}, \hat{\vec{s}}_{\eta} \cdot \vec{r}_{\mathrm{eq}}\right)+\left(\xi_{0}, \eta_{0}\right)
$$

where $\left(\xi_{0}, \eta_{0}\right)$ is some offset depending on the angular distance between the star and the asteroid. The silhouette of a convex model is the convex hull of projected vertices.

\subsection{Scaling the model}

Although the lightcurve inversion models represent the global shape of asteroids well, they are not very detailed and usually do not reveal nonconvex features (Ďrech and Kaasalainen, 2003). The complementary occultation data can add such details in the models. However, only a limited number of observed occultations clearly reveal a distinct nonconvex feature (see
Timerson et al. (2009), for example). For most occultations, the errors of individual chords are too large or the number of chords is too low to enable us to create a reliable nonconvex model. For these reasons, we fix the shape and only scale it as $c \cdot \vec{r}$ to give the best fit to the occultation silhouette. Also the rotation parameters $\left(\lambda_{\mathrm{p}}, \beta_{\mathrm{p}}, \varphi_{0}, P\right)$ are fixed on the values determined by lightcurve inversion. Thus the only free parameters are the scale $c$ and the offset distances $\eta_{0}, \xi_{0}$.

By changing $c, \eta_{0}$, and $\xi_{0}$, we minimize the $\chi^{2}$ measure

$$
\chi^{2}=\sum_{j=1}^{N} \frac{\left[\left(\xi_{j}, \eta_{j}\right)_{\mathrm{occ}}-\left(\xi_{j}, \eta_{j}\right)_{\mathrm{model}}\right]^{2}}{\sigma_{j}^{2}}
$$

where $\left(\xi_{j}, \eta_{j}\right)_{\text {occ }}$ are projections of observed timings onto the fundamental plane, $\left(\xi_{j}, \eta_{j}\right)_{\text {model }}$ are intersections between the projected asteroid's limb and the line going through the point $\left(\xi_{j}, \eta_{j}\right)_{\text {occ }}$ with the direction of occultation chord $\hat{\vec{s}}_{v}$ (or $\left.-\hat{\vec{s}}_{v}\right)$, and $\sigma_{j}$ are errors of $\left(\xi_{j}, \eta_{j}\right)_{\text {occ }}$. The $\hat{\vec{s}}_{v}$ is a unit vector in the direction of the shadow movement on the fundamental plane. We use the JPL Horizons ephemeris system to compute $\hat{\vec{s}}_{v}$ of individual observers with respect to the asteroid.

The main source of error affecting the occultation silhouette points $\left(\xi_{j}, \eta_{j}\right)_{\text {occ }}$ is the timing of dis- and reappearance of the star. Errors in timing propagate to errors in the position on the projection plane that are aligned in the direction of $\hat{\vec{s}}_{v}$. This is the reason why we minimize the difference between the model's silhouette and occultation silhouette along $\hat{\vec{s}}_{v}$ in Eq. (5).

The errors $\sigma_{j}$ are not always reported or even worse, are underestimated. So we often have to choose realistic values. This introduces a subjective aspect into the modelling process. Fortunately, the results derived in the next section are not too sensitive to the particular choice of weighting of individual observations. The uncertainty of timings becomes more important for short occultations - then the uncertainty of the size is dominated by timing errors, not by errors introduced by too simple shape model.

Timings determined visually are affected by observers' reaction times. When the star is relatively bright and easy to see, visual reaction times are less than $\sim 1.5 \mathrm{~s}$. For fainter stars, reaction times of 2 to 3 seconds are possible. Observers estimate their reaction times and correct the timing for this effect. However, systematic errors introduced by this effect are often present, as can be seen when a visual chord is compared with a nearby chord measured electronically. In many cases, the lengths of visual chords are correct, but they are significantly shifted in time with respect to the other chords. For this reason, we allowed visual chords to 'float' along the relative velocity vector $\hat{\vec{s}}_{v}$. This shift in the fundamental plane corresponds to the

\footnotetext{
${ }^{6}$ http://ssd.jpl.nasa.gov/?horizons
} 
shift $\Delta \tau$ in timings. For visual observations, we modified Eq. (2) to

$$
(\xi, \eta)=\left[\hat{\vec{s}}_{\xi} \cdot(\vec{x}+\Delta \vec{v}(\Delta t+\Delta \tau)), \hat{\vec{s}}_{\eta} \cdot(\vec{x}+\Delta \vec{v}(\Delta t+\Delta \tau))\right],
$$

where $\Delta \tau$ are free parameters that are optimized to get the lowest $\chi^{2}$. To avoid too large shifts in time, we include the penalty function

$$
\chi_{\text {new }}^{2}=\chi^{2}+\sum_{i}\left(\frac{\Delta \tau_{i}}{\gamma}\right)^{2},
$$

where $\gamma$ is chosen subjectively to trade-off between the goodness of the fit and the magnitude of the time shift. Usually, $\Delta \tau_{i}$ values of the order of tenths of second are sufficient. In some cases $\Delta \tau_{i}$ are of the order of seconds.

In principle, also some chords observed with video or CCD can be misplaced with respect to other chords due to bad absolute timing. Shifting such chords according to Eq. (6) would improve the fit but one has to be sure that the discrepancy with other chords is caused by bad timing, not by some real features of the shape. We applied the shift only to chords observed visually.

\section{Results}

In this section, we briefly describe all asteroids for which we scaled the shape models to fit the occultation data. We list all occultations used in our analysis in Table 1] For each occultation event, we list the total number of chords $N_{\text {total }}$ we used (that can be lower than the number of observed chords because we sometimes reject clearly erroneous chords), the number of chords $N_{\text {phot }}$ measured photoelectrically, using video, or CCD, the angle $\Delta \phi$ of which the asteroid rotated during the occultation, the mean duration of the event $t_{\text {mean }}$, and the reference to the paper where the occultation results were published. For each occultation observed visually, the average absolute time shift $|\Delta \tau|$ of visual chords (Eq. 6) is listed. Observations that report only one timing (disappearance or reappearance) are counted as individual chords.

Table 2 lists all observers that participated in observations of recent occultations that were not included in the database of Dunham and Herald (2009). We list all observers, including those that reported 'misses'. If some observer provided more than one chord, the number of chords is given in parentheses.

In Table 3, we list the derived equivalent diameter $D$ for each model (which is the diameter of a sphere with the same volume as the shape model) and their estimated errors, the ecliptic latitude $\lambda_{\mathrm{p}}$ and longitude $\beta_{\mathrm{p}}$ of the pole direction, the sidereal rotation period $P$, the diameter $D_{\text {IRAS }}$ derived from the IRAS infrared measurements by Tedesco et al. (2004), the rms residual of the fit with visual chords allowed to move along the relative velocity vector $\left(\mathrm{rms}_{1}\right)$ and with visual chords fixed $\left(\mathrm{rms}_{2}\right)$, and the reference to the paper where the original shape model was

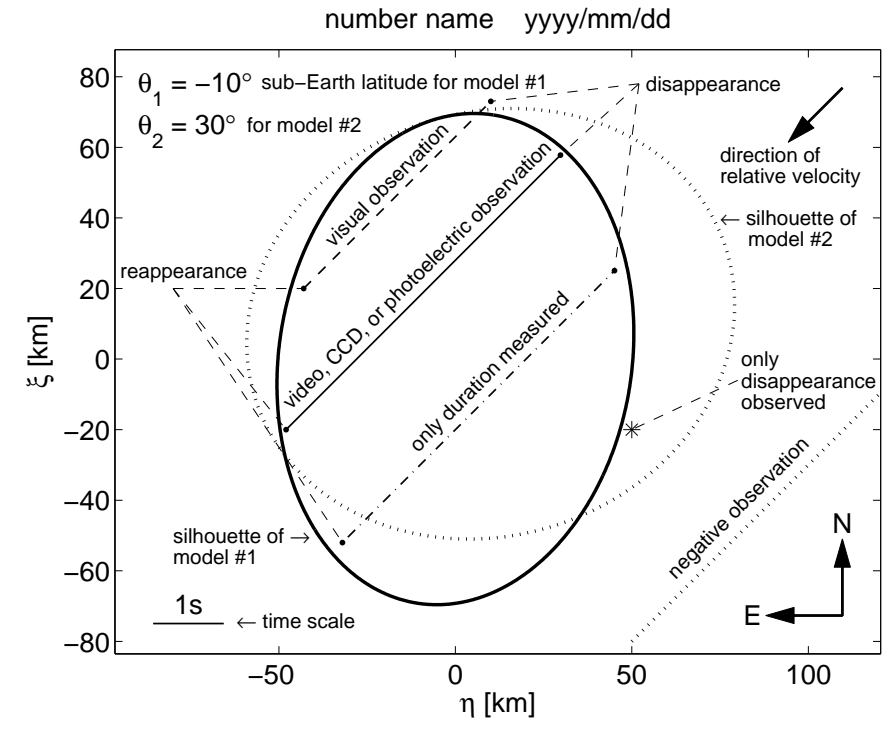

Figure 1: Explanation of line types and symbols used in Figs. 24 45

published. If one of the pole solutions is preferred, the corresponding values are typeset in bold. We estimated the uncertainty of the equivalent size as twice the rms residual of the fit. In cases where the errors in timing are the main source of uncertainty of the diameter (6 Hebe, for example), we estimated the uncertainty of the size by propagating the errors of timings.

For asteroids that have known mass, we could compute the density. However, such density estimates would be biased, beacause the volume of a convex model is larger than the real volume of the asteroid. Therefore we do not provide any density estimations.

In Figs. 24, 45, we plot the projected asteroid silhouettes and the chords used for scaling the model. The meaning of different types of lines and curves is explained in Fig. 1 . If there are two possible pole solutions, one of the corresponding profiles (usually the one that gives a worse fit) is plotted with a dotted curve. Chords observed visually are plotted as dashed lines, others (observed by means of CCD or other photodetector) are plotted as solid lines. Dotted lines represent negative observations and dot-dashed lines represent observations that report only the duration of the event, not absolute timings. Such chords can be arbitrarily shifted in time along the relative velocity vector. If an observer reported only the beginning or the end of the occultation, we plot it as an asterisk. Each plot contains also the time scale and the latitude of the sub-Earth point $\theta$ for the time of occultation and corresponding model. If there are two models in one figure, the visual chords are plotted with shifts (Eq. 6) corresponding to the solid-contour model.

All shape models, spin parameters, and lightcurve data we present are available online in DAMIT. 
(2) Pallas. The occultation of SAO 85009 by asteroid Pallas in 29 May 1978 was one of the first successfully observed occultations with photoelectrically measured timings and a very good coverage of the whole projected silhouette. The next event in 29 May 1983 is the most densely covered occultation ever observed. More than one hundred chords were measured and the size of Pallas was accurately determined (Dunham et al., 1990). The other three events from 1985, 2001, and 2006 provide additional projection geometry.

Two models of Pallas were derived by Torppa et al. (2003), with the preference of the pole $\left(35^{\circ},-12^{\circ}\right)$. Because the shape of Pallas is rather spherical and the occultation did not reveal any distinct features, both models fit the chords almost equally well. However, only one pole solution is consistent with the adaptive optics images by Carry et al. (2010). They derived a nonconvex model of Pallas with the pole direction $\left(30^{\circ},-16^{\circ}\right) \pm 5^{\circ}$ and the equivalent diameter $512 \pm 6 \mathrm{~km}$, which is close to the diameter $539 \pm 28 \mathrm{~km}$ derived from occultations (Fig. 2). Schmidt et al. (2009) derived an ellipsoidal model of Pallas from HST observations. The model has the equivalent diameter of $545 \pm 18 \mathrm{~km}$, which is also consistent with our value.

(3) Juno. The 11 December 1979 occultation event provided excellent photoelectric measurements of 15 chords distributed over the whole projection. The second observed occultation on 24 May 2000 provided only four visual chords and three of them were placed close together. The shape model of Juno derived by Kaasalainen et al. (2002b) fits both occultations well (Fig. 3).

(5) Astraea. A recent occultation by Astraea was observed in 6 June 2008 with the timings determined mainly visually. From the two shape models that were derived by Durech et al. (2009), we can reject the pole $\left(310^{\circ}, 44^{\circ}\right)$, because the shape model with the pole direction $\left(126^{\circ}, 40^{\circ}\right)$ clearly gives a better fit (Fig. 4).

(6) Hebe. The shape model derived by Torppa et al. (2003) agrees with the occultation data. However, scaling of the model is not very accurate, because the occultation duration was only a few seconds and all observations were visual (Fig. 5]).

(7) Iris. The shape model derived by Kaasalainen et al. (2002b) as well as its mirror solution can be scaled to fit the two occultations. The second occultation was short and there were large errors in the visually determined timings (Fig. 6). Ostro et al. (2010) derived from radar observations a shape models of Iris with the equivalent diameter of $208 \pm 35 \mathrm{~km}$ and the pole direction $\lambda=15 \pm 5^{\circ}$ and $\beta=25 \pm 15^{\circ}$ that is consistent with the first model of Iris in Table 3
(8) Flora. Although Torppa et al. (2003) give only one pole solution $\left(160^{\circ}, 16^{\circ}\right)$, the mirror solution at $\left(335^{\circ},-5^{\circ}\right)$ fits the lightcurves equally well and gives a slightly better fit to the occultation chords (Fig. 7).

(9) Metis. The lightcurve inversion led to two possible pole solutions (Torppa et al., 2003), but only one agreed with the adaptive optics images (Marchis et al., 2006). The consistency of this shape model with the occultation chords from 12 September 2008 was demonstrated by Timerson et al. (2009). In Fig. 8 we present the fit to four occultation events.

(10) Hygiea. Hanuš and Durech (2010) derived two possible models of Hygiea by lightcurve inversion of archived data and sparse photometry. Both models fit the occultation data similarly well, but with very different sizes of $351 \mathrm{~km}$ and $443 \mathrm{~km}$ (Fig. 9). The diameter derived from IRAS measurements was $407 \mathrm{~km}$ (Tedesco et al., 2004), which is closer to the second (less preferred) model in Table 3 .

(16) Psyche. Only one of the two models reported by Kaasalainen et al. (2002b) is consistent with the two occultations observed in 2004 and 2010 (Fig. 10). For the occultation from 2004, one chord does not match with the model's profile. This may be caused either by an error in timing or by an error of the shape model.

(17) Thetis. Ďurech et al. (2009) derived two models, but only one, with the pole direction $\left(236^{\circ}, 20^{\circ}\right)$, gives a good match with the occultation chords (Fig. 11).

(22) Kalliope. One of the models derived by Kaasalainen et al. (2002b) with the pole direction $\left(196^{\circ}, 3^{\circ}\right)$ is consistent with the satellite orbit analysis (Descamps et al., 2008) and also with the occultation observed in 2006 (Fig. 12). However, the equivalent diameter $166.2 \pm 2.8 \mathrm{~km}$ derived by Descamps et al. (2008) is significantly larger than our value $143 \pm 10 \mathrm{~km}$.

(28) Bellona. We derived two possible models from the Asteroid Photometric Catalogue (APC) data (Lagerkvist et al., 2001), new observations (Table 4), and US Naval Observatory (USNO) sparse photometry downloaded from the Asteroids Dynamic Site7. Both models give similar fits to the data (Fig. 13).

(34) Circe. Both shape models derived by Durech et al. (2009) are possible, because the four chords observed in 2004 are grouped into two close pairs and do not allow us to select the correct pole. The two models differ significantly in the size (Fig. 14). The formal error of the fit (and thus of the determined size) is only $4 \mathrm{~km}$, but the real uncertainty in the size is at least $\sim 10 \mathrm{~km}$.

${ }^{7}$ http://hamilton.dm.unipi.it/astdys/ 
(39) Laetitia. The shape model derived by Kaasalainen et al. (2002b) agrees very well with the observed silhouette (Fig. 15).

(41) Daphne. The model derived by Kaasalainen et al. (2002a) is consistent with the occultation silhouette (Fig. 16).

(52) Europa. The pole direction $\left(252^{\circ}, 38^{\circ}\right)$ and the corresponding shape model derived by Michałowski et al. (2004) is consistent with the AO image (Marchis et al., 2006) and also with the two occultation events (Fig. 17).

(54) Alexandra. Warner et al. (2008) derived two shape models. The model with the pole direction $\left(318^{\circ}, 23^{\circ}\right)$ fits the chords better but the other pole solution $\left(156^{\circ}, 13^{\circ}\right)$ cannot be rejected (Fig. 18).

(55) Pandora. The shape model derived by Torppa et al. (2003) is consistent with the occultation chords (Fig. 19).

(63) Ausonia. The fit is not very good and there are only three chords observed in 2000 , but the model with the pole $\left(120^{\circ},-15^{\circ}\right)$ fits much better than the second possible pole $\left(305^{\circ},-21^{\circ}\right)$ (Fig. 201). The size determination is not very accurate, the formal error of $18 \mathrm{~km}$ given in Table 3 is only the lowest limit. Our result is in agreement with results of Tanga et al. (2003) based on HST observations, who derived an ellipsoidal model of Ausonia with the pole direction $\left(119^{\circ},-29^{\circ}\right)$ and the equivalent diameter $87 \mathrm{~km}$.

(64) Angelina. We derived a new model of asteroid Angelina from the lightcurves in the APC and sparse data from USNO. From the two pole solutions $\left(137^{\circ}, 14^{\circ}\right)$ and $\left(317^{\circ}, 17^{\circ}\right)$, the former one is preferred, because it fits the chords significantly better that the latter pole (Fig. 21). The negative chord that intersects the silhouette was observed by two independent observers. The model has to be refined by further observations to match better with the occultation. The uncertainty of the size determination is likely to be larger than the formal value determined from the rms residuum.

(68) Leto. The three chords observed during the occultation in 1999 are not enough to distinguish between two pole solution derived by Hanuš and Durech (2010) (Fig. 22). The size is not determined very accurately.

(80) Sappho. The recently observed occultation clearly shows that only one of the two shape solutions derived by Durech et al. (2009) is acceptable (Fig. 23).

(85) Io. We derived a new model that slightly differs from that derived by Torppa et al. (2003) and that is in agreement with all four occultation events (Fig. 24). The negative observation that intersect the model's projection in 7 December 2004 was made visually and is probably wrong.
(88) Thisbe. The mirror pole solution with the pole direction $\left(72^{\circ}, 60^{\circ}\right)$ is preferred over that reported by Torppa et al. (2003), because it not only fits the chords well, but also does not overlap with the negative observations (Fig. 25).

(89) Julia. We derived a new model of this asteroid from archived APC data and sparse photometry from USNO. From three possible pole solutions derived from photometry, only one is fully consistent with the occultation data (Fig. 26).

(95) Arethusa. From lightcurves only, we were not able to derive a unique model. Although the rotation period was determined uniquely, there were four different pole directions and corresponding shapes that all fitted the photometric data equally well. However, when comparing the predicted profiles with the occultation from 2009, only one model with the pole direction $\left(149^{\circ}, 33^{\circ}\right)$ was acceptable (Fig. 27).

(107) Camilla. The three chords observed during the occultation in 2004 allowed only a rough scaling of an updated version of the shape model derived originally by Torppa et al. (2003) (Fig. 28).

(129) Antigone. The projections of the shape model derived by Torppa et al. (2003) are consistent with the three occultations, but the size cannot be fitted well. The size that fits the two occultations from 1985 and 2001 well gives a poor fit to the third occultation form 2009 (Fig. 29). When fitting only the first two occultations, the size is $(118 \pm 14) \mathrm{km}$, while the third event is fitted at best with the equivalent size $(148 \pm 11) \mathrm{km}$. This inconsistency might be caused by albedo variegation (reported by Torppa et al. (2003)) - the real shape is different from the model that assumes that albedo distribution on the surface is uniform.

(130) Elektra. The shape model derived by Durech et al. (2007) agrees well with the six chords observed in 2010 (Fig. 30). The model is also consistent with the adaptive optics images obtained by Marchis et al. (2006).

(152) Atala. A preliminary model was derived by Durech et al. (2009) with two possible spin/shape solutions. Only one model is consistent with the occultation data (Fig. 31). One negative report intersects the model projection at one end. Modifying the model slightly should solve this inconsistency.

(158) Koronis. From two possible spin vector solutions derived by Slivan et al. (2003), only one is consistent with the occultation chords (Fig. 32). However, even this model fails to fit the northernmost chord that is longer than the shape model. 
(165) Loreley. We derived a new model of Loreley with two possible pole directions $\left(174^{\circ}, 29^{\circ}\right)$ and $\left(348^{\circ}, 42^{\circ}\right)$. Only the first pole solution and the corresponding model is consistent with the occultation data (Fig. 33). This new model is different from that published by Durech et al. (2007).

(167) Urda. One of the pole solutions gives a better fit, but the rival pole cannot be rejected (Fig. 34). The negative chord that intersects the model profile at one end was observed visually. The size determination is not very accurate.

(208) Lacrimosa. The four chords do not enable us to clearly reject one of the two possible pole solutions, although the pole $\left(176^{\circ},-68^{\circ}\right)$ is preferred (Fig. 35).

(276) Adelheid. Only three chords, two of them very close to each other, cannot distinguish between two shape models (Fig. 36). Both models fit the occultation equally well.

(302) Clarissa. Hanuš and Ďurech (2010) derived a very elongated shape model of Clarissa. Both pole solutions are consistent with the occultation observed in 2004, one of them fitting very well (Fig. 37). Although the chords were observed using video, the reported timing errors are of tenths of second.

(306) Unitas. Ďurech et al. (2009) derived two possible shape models. Delbo and Tanga (2009) showed that one of them - with the pole direction $\left(79^{\circ},-35^{\circ}\right)$ - was much more consistent with the thermal infrared measurements made by IRAS. They also derived the effective diameter $55-57 \mathrm{~km}$. This is also confirmed by the occultation data (Fig. [38), because the profile corresponding to this pole does not intersect with the negative chord.

(372) Palma. Hanuš and Ďurech (2010) derived two possible shape models of Palma with the pole directions $\left(221^{\circ},-47^{\circ}\right)$ and $\left(44^{\circ}, 17^{\circ}\right)$. The first shape model seems to be consistent with most of the chords observed during two occultations in 2007 and 2009 (Fig. 39), but the southernmost chord from the 2007 event lies far outside the projected best-fit contour of the model. The second model fits well the southernmost chord from 2007, but its fit to the rest of the chords is slightly worse than for the first model.

(409) Aspasia. With six successfully observed occultations, Aspasia has the highest number of occultation events in our set. From the two models derived by Warner et al. (2009), the one with the pole direction $\left(3^{\circ}, 30^{\circ}\right)$ fits the chords observed during two events in 2008 clearly better than the second pole (Fig. 40).

(471) Papagena. From the two possible models derived by Hanuš and Ďurech (2010), only one is consistent with the occultation observed in 1987 (Fig. 41).
(747) Winchester. We updated the model by Marciniak et al. (2009) with new observations by F. Pilcher and A. Galád (Table 4). Lightcurve inversion yields two pole directions. The second pole solution $\left(172^{\circ},-36^{\circ}\right)$ can be rejected, because the shape projection for this pole fits the occultation data significantly worse than the pole $\left(304^{\circ},-60^{\circ}\right)$ (Fig. 42).

(849) Ara. Only one model, out of the two derived by Marciniak et al. (2009), is consistent with the occultation (Fig. 43).

(925) Alphonsina. Hanuš and Ďurech (2010) derived a new model from combined sparse and dense photometry. Although both occultations suffer from large errors in timings, only one of the pole solutions derived from photometry is consistent with the occultations (Fig. 44).

(1263) Varsavia. We derived two new models from USNO sparse photometry but only one was consistent with the occultation data (Fig. 45).

\section{Conclusions}

By combining asteroid shape models derived from photometry with the occultation data, we can obtain unique physical models of asteroids. Lightcurve data enable us to derive asteroid shape and spin state and the occultations are used for scaling the shape and for solving the pole ambiguity. As can be seen from Table 3 , the uncertainty of the effective diameter determination is $\sim 5 \%$ for the best cases with many accurate chords, $\sim 10 \%$ for a typical occultation, and $\sim 20 \%$ for occultations with only a few chords. Contrary to other indirect methods for asteroid size determination, occultation timings are direct 'measurements' of asteroid dimensions.

The number of successfully observed occultations with many chords steadily grows as does the accuracy of timings - observers routinely use video or CCD techniques and the timings are more accurate and free of reaction times. The use of automatic observing stations equipped with a small telescope will revolutionize the way asteroidal occultations are observed (Degenhardt, 2009). Asteroidal occultations are no longer 'sporadic' events, rather they are systematic and reliable astronomical measurements. With the increasing number of asteroid models and successfully observed occultations, we expect that the scaling of models derived by lightcurve inversion using occultations will become routine.

\section{Acknowledgements}

We thank all the observers for their efforts and for providing their observations. We appreciate the help of Jan Mánek, who provided us with a valuable insight into observation and reduction of occultations. We thank 
Benoit Carry, one of the referees, whose critical comments helped us to improve the manuscript. The work of J.Ď. was supported by the grant GACR P209/10/0537 of the Czech Science Foundation and by the Research Program MSM0021620860 of the Ministry of education. The work of M.K. was supported by the Academy of Finland. Funding for B.W. observations at the Palmer Divide Observatory was provided by NASA grant NNX 09AB48G, by National Science Foundation grant AST-1032896, and by a 2007 Gene Shoemaker NEO Grant from the Planetary Society. The work of A.G. was supported by the grant 2/0016/09 of the Slovak Grant Agency for Science VEGA and by the grant 205/09/1107 of the Czech Science Foundation. J.H. was supported by the grant GACR 205/08/H005 and by the grant GAUK 134710 of the Grant agency of the Charles University.

\section{References}

Carry, B., Dumas, C., Kaasalainen, M., Berthier, J., Merline, W. J., Erard, S., Conrad, A., Drummond, J. D., Hestroffer, D., Fulchignoni, M., Fusco, T., Feb. 2010. Physical properties of (2) Pallas. Icarus 205, 460-472.

Degenhardt, S., May 2009. High resolution asteroid profile by multi chord occultation observations. Society for Astronomical Sciences Annual Symposium 28, 19-21.

Delbo, M., Tanga, P., Feb. 2009. Thermal inertia of main belt asteroids smaller than $100 \mathrm{~km}$ from IRAS data. Planetary and Space Science 57, 259-265.

Descamps, P., Marchis, F., Pollock, J., Berthier, J., Birlan, M., Vachier, F., Colas, F., Nov. 2008. 2007 Mutual events within the binary system of (22) Kalliope. Planetary and Space Science 56, $1851-1856$

Drummond, J. D., Cocke, W. J., Apr. 1989. Triaxial ellipsoid dimensions and rotational pole of 2 Pallas from two stellar occultations. Icarus 78, 323-329.

Dunham, D., Feb. 1999. Planetary occulations for 1999. S\&T 97 (2), 106.

Dunham, D. W., Feb. 1998. Planetary occultations for 1998. S\&T $95(2), 86$.

Dunham, D. W., Mar. 2002. Planetary occultations for 2002. S\&T 103 (3), 92-97.

Dunham, D. W., Mar. 2005. Asteroid occultations for March-July 2005. S\&T 109 (3), 70-72.

Dunham, D. W., Jun. 2006. Upcoming asteroid occultations. S\&T $111(6), 63-64$.

Dunham, D. W., Dunham, J. B., Binzel, R. P., Evans, D. S., Freuh, M., Henry, G. W., A'Hearn, M. F., Schnurr, R. G., Betts, R., Haynes, H., Orcutt, R., Bowell, E., Wasserman, L. H., Nye, R. A., Giclas, H. L., Chapman, C. R., Dietz, R. D., Moncivais, C., Douglass, W. T., Parker, D. C., Beish, J. D., Martin, J. O., Monger, D. R., Hubbard, W. B., Reitsema, H. J., Klemola, A. R., Lee, P. D., McNamara, B. R., Maley, P. D., Manly, P., Markworth, N. L., Nolthenius, R., Oswalt, T. D., Smith, J. A., Strother, E. F., Povenmire, H. R., Purrington, R. D., Trenary, C., Schneider, G. H., Schuster, W. J., Moreno, M. A., Guichard, J., Sanchez, G. R., Taylor, G. E., Upgren, A. R., von Flandern, T. C., May 1990. The size and shape of (2) Pallas from the 1983 occultation of 1 Vulpeculae. Astron. J. 99, 1636-1662.

Dunham, D. W., Goffin, E., Manek, J., Federspiel, M., Stone, R., Owen, W., Sep. 2002. Asteroidal occultation results multiply helped by Hipparcos. Memorie della Societa Astronomica Italiana 73,662 .

Dunham, D. W., Herald, D., Jul. 2009. Asteroid Occultations V7.0. NASA Planetary Data System 111.
Ďurech, J., Kaasalainen, M., Jun. 2003. Photometric signatures of highly nonconvex and binary asteroids. Astron. Astrophys. 404, 709-714.

Ďurech, J., Scheirich, P., Kaasalainen, M., Grav, T., Jedicke, R., Denneau, L., 2007. Physical models of asteroid from sparse photometric data. In: Milani, A., Valsecchi, G. B., Vokrouhlický, D. (Eds.), Near Earth Objects, our Celestial Neighbors: Opportunity and Risk. Cambridge University Press, Cambridge, p. 191.

Durech, J., Kaasalainen, M., Warner, B. D., Fauerbach, M., Marks, S. A., Fauvaud, S., Fauvaud, M., Vugnon, J.-M., Pilcher, F., Bernasconi, L., Behrend, R., Jan. 2009. Asteroid models from combined sparse and dense photometric data. Astron. Astrophys. 493, 291-297.

Ďurech, J., Sidorin, V., Kaasalainen, M., Apr. 2010. DAMIT: a database of asteroid models. Astron. Astrophys. 513, A46+.

Hanuš, J., Ďurech, J., Oct. 2010. New asteroid models based on combined dense and sparse photometry. In: Bulletin of the American Astronomical Society. Vol. 42 of Bulletin of the American Astronomical Society. p. 1035.

Kaasalainen, M., Dec. 2003. Unveiling asteroids: International observing project and amateur-professional connection. Journal of the RAS of Canada 97, 283.

Kaasalainen, M., Torppa, J., Sep. 2001. Optimization methods for asteroid lightcurve inversion. I. Shape determination. Icarus 153, 24-36.

Kaasalainen, M., Torppa, J., Muinonen, K., Sep. 2001. Optimization methods for asteroid lightcurve inversion. II. The complete inverse problem. Icarus $153,37-51$.

Kaasalainen, M., Torppa, J., Piironen, J., Mar. 2002a. Binary structures among large asteroids. Astron. Astrophys. 383, L19-L22.

Kaasalainen, M., Torppa, J., Piironen, J., Oct. 2002b. Models of twenty asteroids from photometric data. Icarus 159, 369-395.

Kaasalainen, S., Kaasalainen, M., Piironen, J., Sep. 2005. Ground reference for space remote sensing. Laboratory photometry of an asteroid model. Astron. Astrophys. 440, 1177-1182.

Koschny, D., Drolshagen, G., Bobrinky, N., 2009. The relevance of asteroid occultation measurements to near-Earth objects. In: Hazards of Near-Earth Objects, in press.

Kristensen, L. K., 1984. (9) Metis Okkultationen den 19. Februar 1984. Astronomie \& Raumfahrt 44, 76.

Lagerkvist, C.-I., Piironen, J., Erikson, A., 2001. Asteroid photometric catalogue, fifth update. Uppsala Astronomical Observatory.

Marchis, F., Kaasalainen, M., Hom, E. F. Y., Berthier, J., Enriquez, J., Hestroffer, D., Le Mignant, D., de Pater, I., Nov. 2006. Shape, size and multiplicity of main-belt asteroids. Icarus 185, 39-63.

Marciniak, A., Michałowski, T., Hirsch, R., Polińska, M., Kamiński, K., Kwiatkowski, T., Kryszczyńska, A., Behrend, R., Bernasconi, L., Michałowski, J., Starczewski, S., Fagas, M., Sobkowiak, K., Apr. 2009. Photometry and models of selected main belt asteroids. VI. 160 Una, 747 Winchester, and 849 Ara. Astron. Astrophys. 498, 313-320.

Marciniak, A., Michałowski, T., Kaasalainen, M., Ďurech, J., Polińska, M., Kwiatkowski, T., Kryszczyńska, K., Hirsch, R., Kamiński, K., Fagas, M., Colas, F., Fauvaud, S., Santacana, G., Behrend, R., Roy, R., Oct. 2007. Photometry and models of selected main belt asteroids. IV. 184 Dejopeja, 276 Adelheid, 556 Phyllis. Astron. Astrophys. 473, 633-639.

Michałowski, T., Kwiatkowski, T., Kaasalainen, M., Pych, W., Kryszczyńska, A., Dybczyński, P. A., Velichko, F. P., Erikson, A., Denchev, P., Fauvaud, S., Szabó, G. M., Mar. 2004. Photometry and models of selected main belt asteroids I. 52 Europa, 115 Thyra, and 382 Dodona. Astron. Astrophys. 416, 353-366.

Millis, R. L., Elliot, J. L., 1979. Direct determination of asteroid diameters from occultation observations. In: Gehrels, T., Matthews, M. S. (Eds.), Asteroids. University of Arizona Press, Tucson, pp. 98-118.

Millis, R. L., Wasserman, L. H., Bowell, E., Franz, O. G., White, N. M., Lockwood, G. W., Nye, R., Bertram, R., Klemola, A., Dunham, E., Morrison, D., Feb. 1981. The diameter of Juno from its occultation of $\mathrm{AG}+0^{\circ} 1022$. Astron. J. 86, 306-313.

Millis, R. L., Wasserman, L. H., Franz, O. G., White, N. M., Bowell, 
E., Klemola, A., Elliott, R. C., Smethells, W. G., Price, P. M., McKay, C. P., Steel, D. I., Everhart, E., Everhart, E. M., Feb. 1983. The diameter of 88 Thisbe from its occultation of SAO 187124. Astron. J. 88, 229-235.

Ostro, S. J., Magri, C., Benner, L. A. M., Giorgini, J. D., Nolan, M. C., Hine, A. A., Busch, M. W., Margot, J. L., May 2010. Radar imaging of Asteroid 7 Iris. Icarus 207, 285-294.

Sato, I., Soma, M., Hirose, T., Apr. 1993. The occultation of gamma Geminorum by the asteroid 381 Myrrha. Astron. J. 105, 15531561.

Sato, I., Šarounová, L., Fukushima, H., May 2000. Size and shape of Trojan asteroid Diomedes from its occultation and photometry. Icarus 145, 25-32.

Schmidt, B. E., Thomas, P. C., Bauer, J. M., Li, J., McFadden, L. A., Mutchler, M. J., Radcliffe, S. C., Rivkin, A. S., Russell, C. T., Parker, J. W., Stern, S. A., Oct. 2009. The shape and surface variation of 2 Pallas from the Hubble Space Telescope. Science 326, 275-278.

Shevchenko, V. G., Tedesco, E. F., Sep. 2006. Asteroid albedos deduced from stellar occultations. Icarus 184, 211-220.

Slivan, S. M., Binzel, R. P., Crespo da Silva, L. D., Kaasalainen, M., Lyndaker, M. M., Krčo, M., Apr. 2003. Spin vectors in the Koronis family: comprehensive results from two independent analyses of 213 rotation lightcurves. Icarus 162, 285-307.

Sôma, M., Hayamizu, T., Miyashita, K., Setoguchi, T., Hirose, T., 2007. Occultation by (22) Kalliope and its satellite Linus. In: Proc. International Astronomical Union. Vol. 3. pp. 130-131.

Stamm, J., 1985. Asteroidal appulse and occultation observations. Occ. Newsl. 3, 296-299.

Stamm, J., 1989. Reports of asteroidal appulses and occultations. Occ. Newsl. 5, 327-328.

Tanga, P., Delbo, M., Nov. 2007. Asteroid occultations today and tomorrow: toward the GAIA era. Astron. Astrophys. 474, 10151022 .

Tanga, P., Hestroffer, D., Cellino, A., Lattanzi, M., Di Martino, M., Zappalà, V., Apr. 2003. Asteroid observations with the Hubble Space Telescope. II. Duplicity search and size measurements for 6 asteroids. Astron. Astrophys. 401, 733-741.

Taylor, G. E., Dunham, D. W., Apr. 1978. The size of minor planet 6 Hebe. Icarus 34, 89-92.

Tedesco, E. F., Noah, P. V., Noah, M., Price, S. D., Oct. 2004. IRAS Minor Planet Survey V6.0. NASA Planetary Data System 12.

Thompson, B., Yeelin, T., Dec. 2006. Duplicity in 16 Piscium confirmed from its occultation by 7 Iris on 2006 May 5. Publ. Astron. Soc. Pacific 118, 1648-1655.

Timerson, B., Ďurech, J., Aguirre, S., Benner, L., Blacnhette, D., Breit, D., Campbell, S., Campbell, R., Carlisle, R., Castro, E., Clark, D., Clark, J., Correa, A., Coughlin, K., Degenhardt, S., Dunham, D., Fleishman, R., Frankenberger, R., Gabriel, P., Harris, B., Herald, D., Hicks, M., Hofler, G., Holmes, A., Jones, R., Lambert, R., Lucas, G., Lyzenga, G., Macdougal, C., Maley, P., Morgan, W., Mroz, G., Nolthenius, R., Nugent, R., Preston, S., Rodriguez, C., Royer, R., Sada, P., Sanchez, E., Sanford, B., Sorensen, R., Stanton, R., Venable, R., Vincent, M., Wasson, R., Wilson, E., Jul. 2009. A trio of well-observed asteroid occultations in 2008. Minor Planet Bulletin 36, 98-100.

Torppa, J., Kaasalainen, M., Michalowski, T., Kwiatkowski, T., Kryszczyńska, A., Denchev, P., Kowalski, R., Aug. 2003. Shapes and rotational properties of thirty asteroids from photometric data. Icarus 164, 346-383.

Warner, B. D., Ďurech, J., Fauerbach, M., Marks, S., Oct. 2008. Shape and spin models for four asteroids. Minor Planet Bulletin 35, 167-171.

Warner, B. D., Harris, A. W., Pravec, P., Jul. 2009. The asteroid lightcurve database. Icarus 202, 134-146.

Wasserman, L. H., Millis, R. L., Franz, O., Jun. 1986. The occultation of $\mathrm{AG}+20^{\circ} 1138$ by 129 Antigone on 11 April 1985. Bulletin of the AAS 18, 797 .

Wasserman, L. H., Millis, R. L., Franz, O. G., Bowell, E., White, N. M., Giclas, H. L., Martin, L. J., Elliot, J. L., Dunham, E., Mink, D., Baron, R., Honeycutt, R. K., Henden, A. A., Kephart,
J. E., A'Hearn, M. F., Reitsema, H. J., Radick, R., Taylor, G. E., Feb. 1979. The diameter of Pallas from its occultation of SAO 85009. Astron. J. 84, 259-268. 
List of occultations

\begin{tabular}{|c|c|c|c|c|c|c|c|c|}
\hline \multirow[t]{2}{*}{ Asteroid } & \multirow[t]{2}{*}{ Date } & \multirow[t]{2}{*}{$N_{\text {total }}$} & \multirow[t]{2}{*}{$N_{\text {phot }}$} & \multirow{2}{*}{$\begin{array}{c}\Delta \phi \\
{[\mathrm{deg}]}\end{array}$} & \multirow{2}{*}{$\begin{array}{c}t_{\text {mean }} \\
{[\mathrm{s}]}\end{array}$} & \multicolumn{2}{|c|}{$|\Delta \tau|[\mathrm{s}]$} & \multirow[t]{2}{*}{ Reference } \\
\hline & & & & & & model 1 & model 2 & \\
\hline \multirow[t]{5}{*}{2 Pallas } & $1978 / 05 / 29$ & 8 & 8 & 2.6 & 30.1 & & & Wasserman et al. (1979) \\
\hline & $1983 / 05 / 29$ & 121 & 18 & 2.5 & 34.4 & 0.24 & & Dunham et al. (1990) \\
\hline & $1985 / 10 / 24$ & 3 & 0 & 0.4 & 27.9 & 0.02 & & Stamm (1985) \\
\hline & 2001/06/09 & 3 & 3 & 0.8 & 25.1 & & & \\
\hline & 2006/06/12 & 4 & 4 & 0.5 & 35.4 & & & \\
\hline \multirow[t]{2}{*}{3 Juno } & $1979 / 12 / 11$ & 17 & 14 & 13.6 & 57.6 & 1.42 & & Millis et al. (1981) \\
\hline & $2000 / 05 / 24$ & 5 & 0 & 0.6 & 17.0 & 0.19 & & \\
\hline 5 Astraea & $2008 / 06 / 06$ & 13 & 3 & 0.3 & 13.8 & 0.11 & 0.23 & \\
\hline 6 Hebe & $1977 / 03 / 05$ & 5 & 0 & 0.1 & 3.3 & 0.12 & & Tavlor and Dunham (1978) \\
\hline \multirow[t]{2}{*}{7 Iris } & $2005 / 02 / 17$ & 4 & 0 & 0.1 & 7.2 & 0.20 & 0.12 & \\
\hline & $2006 / 05 / 05$ & 4 & 1 & 0.1 & 4.2 & 0.59 & 0.54 & Thompson and Yeelin (2006) \\
\hline 8 Flora & $2004 / 10 / 29$ & 7 & 6 & 0.1 & 6.2 & 0.03 & 0.27 & Dunham (2005) \\
\hline \multirow[t]{4}{*}{9 Metis } & $1984 / 02 / 19$ & 8 & 1 & 1.2 & 16.6 & 0.98 & & Kristensen (1984) \\
\hline & $1989 / 08 / 06$ & 5 & 1 & 3.2 & 12.7 & 0.31 & & Stamm (1989) \\
\hline & $2001 / 09 / 07$ & 7 & 5 & 0.2 & 3.1 & 0.07 & & Dunham (2002) \\
\hline & $2008 / 09 / 12$ & 20 & 15 & 1.8 & 35.5 & 0.67 & & Timerson et al. (2009) \\
\hline 10 Hygiea & $2002 / 09 / 07$ & 8 & 6 & 1.9 & 110.1 & 0.66 & 2.17 & \\
\hline \multirow[t]{2}{*}{16 Psyche } & $2004 / 05 / 16$ & 4 & 1 & 0.7 & 12.9 & 0.15 & 0.30 & \\
\hline & $2010 / 08 / 21$ & 14 & 14 & 1.9 & 7.1 & & & \\
\hline 17 Thetis & $2007 / 04 / 21$ & 16 & 9 & 0.6 & 6.0 & 0.59 & 0.46 & Koschnv et al. (2009) \\
\hline 22 Kalliope & $2006 / 11 / 07$ & 8 & 5 & 1.4 & 24.2 & 0.53 & & Sôma et al. (2007) \\
\hline 28 Bellona & $2002 / 05 / 05$ & 8 & 4 & 0.7 & 8.1 & 0.47 & 0.54 & \\
\hline 34 Circe & $2004 / 02 / 10$ & 4 & 4 & 0.4 & 29.1 & & & \\
\hline 39 Laetitia & $1998 / 03 / 21$ & 19 & 2 & 1.4 & 9.7 & 0.37 & & Dunham (1999) \\
\hline 41 Daphne & $1999 / 07 / 02$ & 16 & 3 & 3.6 & 32.7 & 0.50 & & Dunham et al. (2002) \\
\hline \multirow[t]{2}{*}{52 Europa } & $1983 / 04 / 26$ & 10 & 2 & 0.8 & 9.5 & 0.47 & & \\
\hline & $2005 / 12 / 03$ & 12 & 10 & 0.4 & 6.7 & 0.08 & & \\
\hline 54 Alexandra & $2005 / 05 / 17$ & 11 & 6 & 10.3 & 41.7 & 0.22 & 0.04 & Dunham (2006) \\
\hline 55 Pandora & $2007 / 02 / 18$ & 9 & 5 & 3.0 & 3.8 & 0.63 & & \\
\hline 63 Ausonia & $2000 / 12 / 22$ & 3 & 3 & 0.2 & 2.3 & & & \\
\hline 64 Angelina & $2004 / 07 / 03$ & 6 & 6 & 0.0 & 1.2 & & & \\
\hline 68 Leto & $1999 / 05 / 23$ & 3 & 1 & 0.1 & 5.5 & 0.10 & 0.19 & \\
\hline 80 Sappho & $2010 / 06 / 04$ & 11 & 9 & 1.0 & 5.6 & 0.94 & 0.24 & \\
\hline \multirow[t]{4}{*}{85 Io } & $1995 / 12 / 10$ & 8 & 0 & 3.7 & 15.6 & 0.30 & & Dunham (1998) \\
\hline & $2004 / 12 / 07$ & 5 & 4 & 0.7 & 13.8 & 0.36 & & \\
\hline & $2004 / 12 / 12$ & 15 & 9 & 1.4 & 12.2 & 0.10 & & \\
\hline & $2005 / 05 / 15$ & 2 & 2 & 0.1 & 4.3 & & & \\
\hline \multirow[t]{2}{*}{88 Thisbe } & $1981 / 10 / 07$ & 12 & 0 & 1.2 & 9.8 & 0.32 & 0.35 & Millis et al. (1983) \\
\hline & $2007 / 02 / 21$ & 6 & 3 & 3.7 & 14.0 & 0.52 & 0.85 & \\
\hline \multirow[t]{2}{*}{89 Julia } & $2005 / 08 / 13$ & 6 & 1 & 1.9 & 7.6 & 0.06 & & \\
\hline & $2006 / 12 / 04$ & 4 & 4 & 0.2 & 9.0 & & & \\
\hline 95 Arethusa & $2009 / 03 / 07$ & 8 & 5 & 0.6 & 8.5 & 0.29 & & \\
\hline 107 Camilla & $2004 / 09 / 05$ & 3 & 3 & 1.3 & 12.3 & & & \\
\hline 129 Antigone & $1985 / 04 / 11$ & 5 & 3 & 4.0 & 69.5 & 6.75 & & Wasserman et al. (1986) \\
\hline & $2001 / 09 / 09$ & 5 & 0 & 2.5 & 8.4 & 0.23 & & \\
\hline & $2009 / 02 / 13$ & 4 & 4 & 1.8 & 7.9 & & & \\
\hline 130 Elektra & $2010 / 02 / 20$ & 7 & 6 & 0.7 & 11.7 & & & \\
\hline 152 Atala & $2006 / 05 / 07$ & 8 & 5 & 7.5 & 3.3 & 0.69 & 0.75 & \\
\hline 158 Koronis & $2005 / 12 / 13$ & 7 & 4 & 0.1 & 1.4 & 0.10 & 0.12 & \\
\hline 165 Loreley & $2009 / 06 / 29$ & 5 & 4 & 0.6 & 33.0 & 0.29 & 0.08 & \\
\hline 167 Urda & $2001 / 07 / 23$ & 3 & 2 & 0.1 & 3.3 & 0.08 & 0.01 & \\
\hline 208 Lacrimosa & $2003 / 12 / 31$ & 5 & 2 & 0.2 & 4.6 & 0.14 & 0.30 & \\
\hline 276 Adelheid & $2002 / 03 / 09$ & 3 & 1 & 1.3 & 5.7 & 0.41 & 0.45 & \\
\hline
\end{tabular}


List of occultations

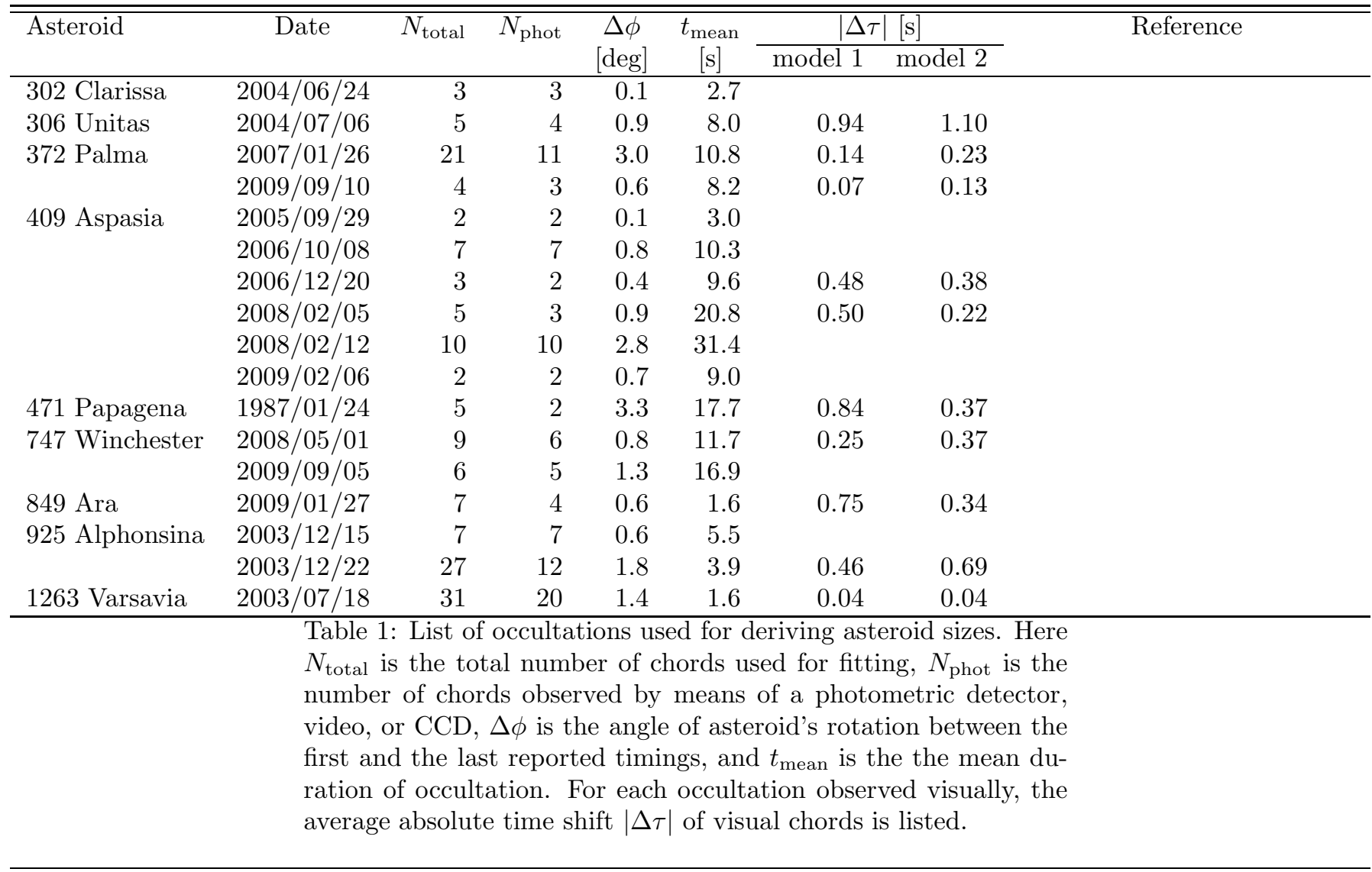




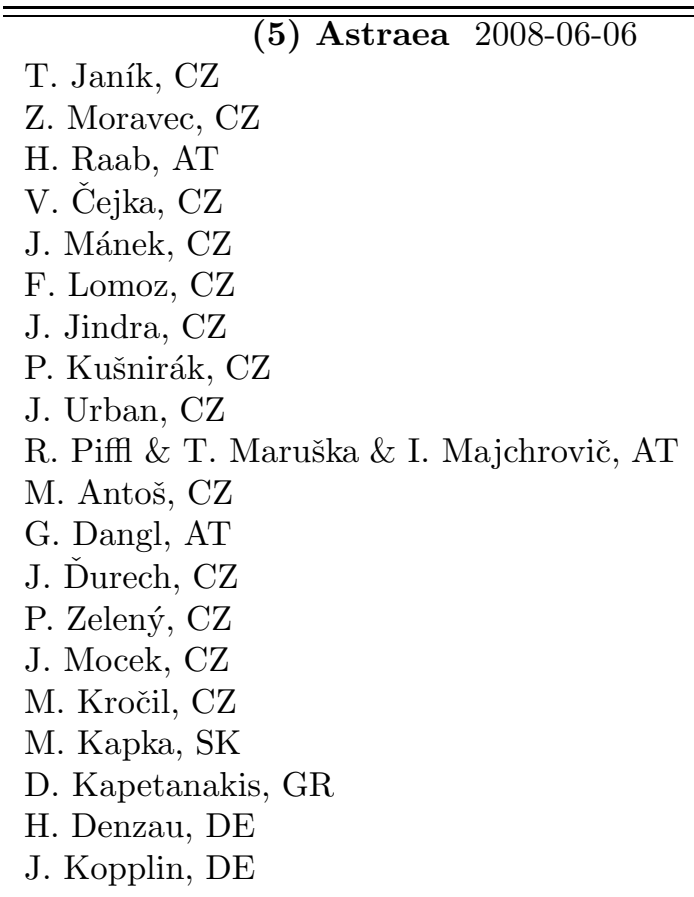

(16) Psyche 2010-08-21

J. Brooks, Winchester, VA, USA

S. Conard, Gamber, MD, USA

D. Dunham, Seymour, TX, USA (5)

A. Scheck, Scaggsville, MD, USA

C. Ellington, Highland Village, TX, USA

P. Maley, Annetta South, TX, USA

R. Tatum, Richmond, VA, USA

P. Maley, Godley, TX, USA

H. \& K. Abramson, Mechanicsville, VA, USA

D. Caton, Boone, NC, USA

E. Iverson, Athens, TX, USA

R. Suggs \& B. Cooke, Huntsville, AL, USA

J. Faircloth, Kinston, NC, USA

P. Birtwhistle, UK

C. Ratinaud, FR

T. Haymes, UK

J. Lecacheux, FR

G. Regheere, FR

O. Dechambre FR

F. Vachier \& S. Vaillant \& J. Berthier, FR

T. Midavaine, FR

E. Bredner \& F. Colas, FR

A. Leroy \& S. Bouley \& R. Palmade \& G. Canaud, FR

E. Frappa, FR

G. Bonatti \& D. Del Vecchio, IT

P. Baruffetti \& A. Bugliani \& G. Tonlorenzi, IT

(95) Arethusa 2009-03-07

A. Carcich, Wantage, NJ, USA

W. Rauscher, Doylestown, PA, USA 
G. Nason, West Lorne, ON, Canada

R. Sauder, Narvon, PA, USA

S. Conard, Gamber, MD, USA

B. Huxtable, Gambrills, MD, USA

D. Dunham, MD \& VA, USA (3)

H. Abramson, Smithfield, VA, USA

(129) Antigone 2009-02-13

R. Cadmus, Grinnell, IA, USA

A. Carcich, Lacey, NJ, USA

S. Messner, Morning Sun, IA, USA

D. Dunham, Glen Rock, PA, USA

S. Conard, Gamber, MD, USA

B. Huxtable,Gambrills, MD, USA

A. Olsen, Urbana, IL, USA

A. Elliott, UK

(130) Elektra 2010-02-20

C. Ratinaud, FR

R. Miles, UK

M. Cole, UK

A. Pratt, UK

P. Birtwhistle, UK

T. Haymes, UK

J.-M. Winkel, NL

R. \& E. Simonson, UK

G. Rousseau, FR

(165) Loreley 2009-06-29

R. Peterson, Scottsdale, AZ, USA

W. Morgan, Wilton, CA, USA

D. Machholz, Colfax, CA, USA

D. Dunham, Blue Canyon, CA \& NV, USA

(372) Palma 2009-09-10

D. Herald, Kambah, ACT, AU

H. Pavlov, Marsfield, AU

D. Gault, Hawkesbury Heights, AU

J. Broughton, Reedy Creek, QLD, AU

C. Wyatt, Walcha, NSW, AU

J. Bradshaw, Samford, QLD, AU

C. Ninet, FR

M. Boutet, FR

J. Sanchez, FR

G. Faure, FR

E. Frappa, FR

S. Bolzoni, IT

S. Sposetti, CH

G. Sbarufatti, IT

R. Di Luca, IT

(409) Aspasia 2008-02-12

J. Denis, FR 


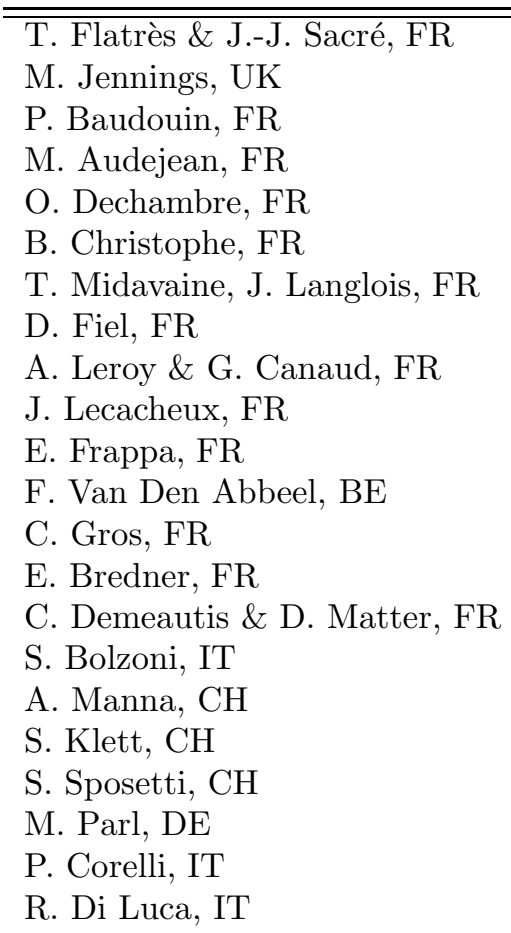

(409) Aspasia 2009-02-06

D. Snyder, Bisbee, AZ, USA

P. Sada, Observatorio UDEM, Mexico

(747) Winchester 2008-05-01

D. Koschny, NL

H. De Groot, NL

A. Scholten, NL

H. Rutten, NL

M. Rain, DE

E. Frappa \& A. Klotz, FR

H. Bill \& M. Jung, DE

J. Müller \& U. Appel, DE

W. Rothe, DE

I. Majchrovič \& R. Piffl, SK

A. Galád, SK

T. Pauwels \& P. De Cat, BE

(747) Winchester 2009-09-05

D. Gault, Macquarie Woods, NSW, AU

J. Broughton, Reedy Creek, QLD, AU

D. Lowe, Leyburn, QLD, AU

S. Quirk, Mudgee, NSW, AU

P. Purcell, Weston Creek, ACT, AU

D. Herald, ACT, AU (2)

C. Wyatt, Narrabri, NSW, AU

J. Betts, Hawkesbury Heights, NSW, AU

S. Russell, Orange, NSW, AU

(849) Ara 2009-01-27

R. Stanton, Three Rivers, CA, USA

D. Breit, Morgan Hill, CA, USA 
List of observers

R. Royer, Springville, CA, USA

R. Nolthenius, Cabrillo College, CA, USA

B. Stine, Weldon, CA, USA

R. Peterson, AZ, USA (2)

Table 2: List of observers who participated in observations presented in Table 1 that were not included in the database published by Dunham and Herald (2009). If some observer provided more than one chord, the number of chords is given in parentheses. 
List of results

\begin{tabular}{|c|c|c|c|c|c|c|c|c|}
\hline Asteroid & $\begin{array}{c}D \\
{[\mathrm{~km}]}\end{array}$ & $\begin{array}{c}\lambda_{\mathrm{p}} \\
{[\mathrm{deg}]}\end{array}$ & $\begin{array}{c}\beta_{\mathrm{p}} \\
{[\mathrm{deg}]}\end{array}$ & $\begin{array}{c}P \\
{[\mathrm{hr}]}\end{array}$ & $\begin{array}{c}D_{\text {IRAS }} \\
{[\mathrm{km}]}\end{array}$ & $\begin{array}{l}\mathrm{rms}_{1} \\
{[\mathrm{~km}]}\end{array}$ & $\begin{array}{l}\mathrm{rms}_{2} \\
{[\mathrm{~km}]}\end{array}$ & "Reference \\
\hline 2 Pallas & $539 \pm 28$ & 35 & -12 & 7.81323 & $498 \pm 19$ & 14.2 & 16.6 & Torppa et al. (2003) \\
\hline 3 Juno & $252 \pm 29$ & 103 & 27 & 7.209531 & $234 \pm 11$ & 14.3 & 17.4 & Kaasalainen et al. (2002b) \\
\hline 5 Astraea & $115 \pm 6$ & 126 & 40 & 16.80061 & $119 \pm 7$ & 3.2 & 3.4 & Ďurech et al. (2009) \\
\hline 6 Hebe & $180 \pm 40$ & 340 & 42 & 7.274471 & $185 \pm 3$ & 7.7 & 9.5 & Torppa et al. (2003) \\
\hline \multirow[t]{2}{*}{7 Iris } & $198 \pm 27$ & 20 & 14 & 7.138840 & $200 \pm 10$ & 13.7 & 26.2 & Kaasalainen et al. (2002b) \\
\hline & $199 \pm 26$ & 199 & -2 & & & 13.2 & 27.7 & \\
\hline \multirow[t]{2}{*}{8 Flora } & $141 \pm 10$ & 155 & 6 & 12.86667 & $136 \pm 2$ & 4.8 & 5.1 & Torppa et al. (2003) \\
\hline & $140 \pm 7$ & 335 & -5 & & & 3.7 & 3.8 & \\
\hline 9 Metis & $169 \pm 20$ & 180 & 22 & 5.079176 & & 10.2 & 12.4 & $\begin{array}{l}\text { Torppa et al. (2003) } \\
\text { Timerson et al. }(2009)\end{array}$ \\
\hline \multirow[t]{2}{*}{10 Hygiea } & $351 \pm 27$ & 122 & -44 & 27.65905 & $407 \pm 7$ & 13.8 & 14.0 & Hanuš and Ďurech (2010) \\
\hline & $443 \pm 45$ & 312 & -42 & & & 22.5 & 24.1 & \\
\hline \multirow[t]{2}{*}{16 Psyche } & $225 \pm 20$ & 33 & -7 & 4.195948 & $253 \pm 4$ & 10.0 & 11.1 & Kaasalainen et al. (2002b) \\
\hline & $225 \pm 36$ & 213 & 1 & & & 17.8 & 18.0 & \\
\hline 17 Thetis & $77 \pm 8$ & 236 & 20 & 12.26603 & $90 \pm 4$ & 4.0 & 6.1 & Ďurech et al. (2009) \\
\hline 22 Kalliope & $143 \pm 10$ & 196 & 3 & 4.148200 & $181 \pm 5$ & 5.1 & 5.7 & Kaasalainen et al. (2002b) \\
\hline \multirow[t]{2}{*}{28 Bellona } & $97 \pm 11$ & 282 & 6 & 15.70785 & $121 \pm 3$ & 5.4 & 5.8 & this work \\
\hline & $100 \pm 10$ & 102 & -8 & & & 5.1 & 6.1 & \\
\hline \multirow[t]{2}{*}{34 Circe } & $96 \pm 10$ & 94 & 35 & 12.17458 & $114 \pm 3$ & 1.8 & & Ďurech et al. (2009) \\
\hline & $107 \pm 10$ & 275 & 51 & & & 2.0 & & \\
\hline 39 Laetitia & $163 \pm 12$ & 323 & 32 & 5.138238 & $150 \pm 9$ & 6.2 & 14.4 & Kaasalainen et al. (2002b) \\
\hline 41 Daphne & $187 \pm 20$ & 198 & -32 & 5.98798 & $174 \pm 12$ & 10.2 & 11.0 & Kaasalainen et al. (2002a) \\
\hline 52 Europa & $293 \pm 30$ & 251 & 35 & 5.629958 & $303 \pm 5$ & 14.9 & 16.5 & Michałowski et al. (2004) \\
\hline \multirow[t]{2}{*}{54 Alexandra } & $135 \pm 20$ & 156 & 13 & 7.022641 & $166 \pm 3$ & 10.1 & 10.1 & Warner et al. (2008) \\
\hline & $142 \pm 9$ & 318 & 23 & 7.022649 & & 4.7 & 4.9 & \\
\hline 55 Pandora & $70 \pm 7$ & 223 & 18 & 4.804043 & $67 \pm 3$ & 3.3 & 6.0 & Torppa et al. (2003) \\
\hline 63 Ausonia & $90 \pm 18$ & 120 & -15 & 9.29759 & $103 \pm 2$ & 8.9 & & Torppa et al. (2003) \\
\hline \multirow[t]{2}{*}{64 Angelina } & $51 \pm 10$ & 317 & 17 & 8.75032 & & 5.1 & & this work \\
\hline & $52 \pm 10$ & 137 & 14 & & & 2.7 & & \\
\hline \multirow[t]{2}{*}{68 Leto } & $148 \pm 25$ & 103 & 43 & 14.84547 & $123 \pm 5$ & 6.5 & 8.3 & Hanuš and Ďurech (2010) \\
\hline & $151 \pm 25$ & 290 & 23 & & & 12.6 & 15.9 & \\
\hline 80 Sappho & $67 \pm 11$ & 194 & -26 & 14.03087 & $78 \pm 2$ & 5.6 & 8.1 & Ďurech et al. (2009) \\
\hline 85 Io & $163 \pm 15$ & 95 & -65 & 6.874783 & $155 \pm 4$ & 7.4 & 7.9 & this work \\
\hline \multirow[t]{2}{*}{88 Thisbe } & $204 \pm 14$ & 72 & 60 & 6.04131 & $201 \pm 5$ & 7.1 & 12.5 & this work \\
\hline & $220 \pm 16$ & 247 & 50 & & & 6.5 & 13.9 & Torppa et al. (2003) \\
\hline 89 Julia & $140 \pm 10$ & 8 & -13 & 11.38834 & $151 \pm 3$ & 4.8 & 5.0 & this work \\
\hline 95 Arethusa & $147 \pm 32$ & 149 & 33 & 8.70221 & $136 \pm 10$ & 15.8 & 18.7 & this work \\
\hline 107 Camilla & $214 \pm 28$ & 73 & 54 & 4.843928 & $223 \pm 17$ & 14.2 & & Torppa et al. (2003) \\
\hline 129 Antigone & $118 \pm 19$ & 207 & 58 & 4.957154 & & 9.4 & 10.7 & Torppa et al. (2003) \\
\hline 130 Elektra & $191 \pm 14$ & 64 & -88 & 5.224664 & $182 \pm 12$ & 7.2 & & Ďurech et al. (2007) \\
\hline 152 Atala & $65 \pm 8$ & 347 & 47 & 6.24472 & & 3.9 & 9.3 & Ďurech et al. (2009) \\
\hline 158 Koronis & $38 \pm 5$ & 30 & -64 & 14.20569 & $35 \pm 1$ & 1.7 & 2.4 & Slivan et al. (2003) \\
\hline 165 Loreley & $171 \pm 8$ & 174 & 29 & 7.224387 & $155 \pm 5$ & 3.9 & 4.2 & this work \\
\hline \multirow[t]{2}{*}{167 Urda } & $51 \pm 15$ & 107 & -69 & 13.06133 & $40 \pm 2$ & 1.2 & 2.0 & Slivan et al. (2003) \\
\hline & $44 \pm 15$ & 249 & -68 & & & 1.1 & 1.4 & Warner et al. (2008) \\
\hline \multirow[t]{2}{*}{208 Lacrimosa } & $45 \pm 10$ & 20 & -75 & 14.0769 & $41 \pm 2$ & 3.7 & 5.6 & Slivan et al. (2003) \\
\hline & $45 \pm 10$ & 176 & -68 & & & 1.7 & 2.4 & \\
\hline \multirow[t]{2}{*}{276 Adelheid } & $125 \pm 15$ & 9 & -4 & 6.31920 & $122 \pm 8$ & 5.0 & 8.9 & Marciniak et al. (2007) \\
\hline & $117 \pm 15$ & 199 & -20 & & & 4.8 & 9.5 & \\
\hline \multirow[t]{2}{*}{302 Clarissa } & $43 \pm 4$ & 28 & -72 & 14.47670 & $39 \pm 3$ & 2.0 & & Hanuš and Ďurech (2010) \\
\hline & $43 \pm 11$ & 190 & -72 & & & 5.5 & & \\
\hline \multirow[t]{2}{*}{306 Unitas } & $49 \pm 5$ & 79 & -35 & 8.73875 & $47 \pm 2$ & 1.4 & 2.7 & Ďurech et al. (2009) \\
\hline & $53 \pm 5$ & 253 & -17 & & & 1.6 & 3.2 & \\
\hline
\end{tabular}


List of results

\begin{tabular}{|c|c|c|c|c|c|c|c|c|}
\hline$\overline{\text { Asteroid }}$ & $\begin{array}{c}D \\
{[\mathrm{~km}]}\end{array}$ & $\begin{array}{c}\lambda_{\mathrm{p}} \\
{[\mathrm{deg}]}\end{array}$ & $\begin{array}{c}\beta_{\mathrm{p}} \\
{[\mathrm{deg}]}\end{array}$ & $\begin{array}{c}P \\
{[\mathrm{hr}]}\end{array}$ & $\begin{array}{c}D_{\text {IRAS }} \\
{[\mathrm{km}]}\end{array}$ & $\begin{array}{l}\mathrm{rms}_{1} \\
{[\mathrm{~km}]}\end{array}$ & $\begin{array}{l}\mathrm{rms}_{2} \\
{[\mathrm{~km}]}\end{array}$ & Reference \\
\hline \multirow[t]{2}{*}{372 Palma } & $187 \pm 20$ & 221 & -47 & 8.58189 & \multirow[t]{2}{*}{$189 \pm 3$} & 10.1 & 10.6 & \multirow{2}{*}{ Hanuš and Durech (2010) } \\
\hline & $198 \pm 26$ & 44 & 17 & 8.58191 & & 13.2 & 13.8 & \\
\hline 409 Aspasia & $173 \pm 17$ & 3 & 30 & 9.02145 & $162 \pm 7$ & 8.7 & 10.5 & Warner et al. (2008) \\
\hline 471 Papagena & $137 \pm 25$ & 223 & 67 & 7.11539 & $134 \pm 5$ & 12.4 & 15.5 & Hanuš and Ďurech (2010) \\
\hline 747 Winchester & $171 \pm 15$ & 304 & -60 & 9.41480 & $172 \pm 3$ & 7.6 & 8.3 & $\begin{array}{l}\text { Marciniak et al. (2009) } \\
\text { this work }\end{array}$ \\
\hline 849 Ara & $76 \pm 14$ & 223 & -40 & 4.116391 & $62 \pm 3$ & 7.0 & 17.8 & Marciniak et al. (2009) \\
\hline 925 Alphonsina & $58 \pm 16$ & 294 & 41 & 7.87754 & $54 \pm 3$ & 8.0 & 11.5 & Hanuš and Ďurech (2010) \\
\hline 1263 Varsavia & $41 \pm 8$ & 341 & -14 & 7.16495 & $49 \pm 1$ & 3.9 & 4.0 & this work \\
\hline & $\begin{array}{l}\text { Table } \\
\text { mated } \\
\text { the sic } \\
\text { the IR } \\
\text { residu } \\
\text { tive ve } \\
\text { the ref } \\
\text { lished. } \\
\text { shape }\end{array}$ & $\begin{array}{l}\text { : The } \\
\text { ancerts } \\
\text { real ro } \\
\mathrm{S} \text { infr } \\
\text { of the } \\
\text { city } \mathrm{v} \\
\text { rence } \mathrm{t} \\
\text { If one } \\
\text { lodel } \mathrm{i}\end{array}$ & $\begin{array}{l}\text { able l } \\
\text { nty, th } \\
\text { ation } \\
\text { ed me } \\
\text { it with } \\
\text { tor (r } \\
\text { the pa } \\
\text { two p } \\
\text { prefer }\end{array}$ & $\begin{array}{l}\text { s the equi } \\
\text { spin vecto } \\
\text { riod } P \text {, tl } \\
\text { urements } \\
\text { isual choro } \\
\text { 1) and wit } \\
\text { r, where t } \\
\text { sible pole } \\
\text { d, it is pri }\end{array}$ & $\begin{array}{l}\text { ent diar } \\
\text { cliptic c } \\
\text { diamete } \\
\text { Tedesco } \\
\text { allowed t } \\
\text { visual ch } \\
\text { original } \\
\text { ections } \\
\text { d in bol }\end{array}$ & $\begin{array}{l}\text { ter } D \\
\text { rdinat } \\
D_{\text {IRAS }} \\
\text { t al. (2 } \\
\text { move } \\
\text { ds fixe } \\
\text { lape m } \\
\text { d the } \\
\text { font. }\end{array}$ & $\begin{array}{l}\text { vith it } \\
\text { s } \lambda_{\mathrm{p}} \\
\text { derived } \\
04), \text { th } \\
\text { ong th } \\
\left(\mathrm{rms}_{2}\right. \\
\text { del wa } \\
\text { rrespo }\end{array}$ & $\begin{array}{l}\text { esti- } \\
\mathrm{d} \beta_{\mathrm{p}} \text {, } \\
\text { from } \\
\text { rms } \\
\text { rela- } \\
\text {, and } \\
\text { pub- } \\
\text { ading }\end{array}$ \\
\hline
\end{tabular}


Aspect data for new observations

\begin{tabular}{|c|c|c|c|c|c|c|}
\hline$\overline{\text { Date }}$ & $\begin{array}{c}r \\
{[\mathrm{AU}]}\end{array}$ & $\begin{array}{c}\Delta \\
{[\mathrm{AU}]}\end{array}$ & $\begin{array}{c}\alpha \\
{[\mathrm{deg}]}\end{array}$ & $\begin{array}{c}\lambda \\
{[\mathrm{deg}]}\end{array}$ & $\begin{array}{c}\beta \\
{[\mathrm{deg}]}\end{array}$ & Observer \\
\hline \multicolumn{7}{|c|}{ (28) Bellona } \\
\hline 20070428.2 & 2.635 & 1.684 & 9.0 & 196.8 & 12.8 & Warner \\
\hline 20070429.3 & 2.637 & 1.690 & 9.4 & 196.6 & 12.8 & Warner \\
\hline 20070504.3 & 2.644 & 1.723 & 11.0 & 195.8 & 12.8 & Warner \\
\hline 20070510.2 & 2.653 & 1.770 & 13.0 & 195.0 & 12.6 & Warner \\
\hline 20080606.3 & 3.143 & 2.297 & 12.0 & 295.0 & 8.5 & Pilcher \\
\hline 20080607.3 & 3.144 & 2.288 & 11.7 & 294.9 & 8.5 & Pilcher \\
\hline 20080610.3 & 3.146 & 2.265 & 10.9 & 294.5 & 8.6 & Pilcher \\
\hline 20080614.3 & 3.148 & 2.237 & 9.7 & 293.9 & 8.6 & Pilcher \\
\hline 20080624.3 & 3.154 & 2.184 & 6.6 & 292.2 & 8.5 & Pilcher \\
\hline 20080702.3 & 3.159 & 2.160 & 4.2 & 290.6 & 8.3 & Pilcher \\
\hline 20080706.3 & 3.161 & 2.154 & 3.1 & 289.8 & 8.2 & Pilcher \\
\hline 20080802.2 & 3.174 & 2.234 & 8.3 & 284.4 & 7.1 & Pilcher \\
\hline 20101216.4 & 2.385 & 1.517 & 14.0 & 118.9 & -9.4 & Pilcher \\
\hline 20101219.3 & 2.383 & 1.495 & 12.9 & 118.5 & -9.4 & Pilcher \\
\hline 20101222.4 & 2.382 & 1.474 & 11.6 & 118.1 & -9.3 & Pilcher \\
\hline \multicolumn{7}{|c|}{ (747) Winchester } \\
\hline 20080509.3 & 3.949 & 3.031 & 7.0 & 246.7 & 22.3 & Pilcher \\
\hline 20080512.3 & 3.946 & 3.015 & 6.5 & 246.1 & 22.4 & Pilcher \\
\hline 20080513.3 & 3.945 & 3.011 & 6.4 & 245.9 & 22.4 & Pilcher \\
\hline 20080526.3 & 3.932 & 2.976 & 5.6 & 243.3 & 22.4 & Pilcher \\
\hline 20080527.9 & 3.930 & 2.975 & 5.7 & 243.0 & 22.3 & Galád \\
\hline 20080528.9 & 3.929 & 2.975 & 5.7 & 242.8 & 22.3 & Galád \\
\hline 20080529.9 & 3.928 & 2.975 & 5.8 & 242.6 & 22.3 & Galád \\
\hline 20080530.9 & 3.927 & 2.975 & 5.9 & 242.4 & 22.2 & Galád \\
\hline
\end{tabular}



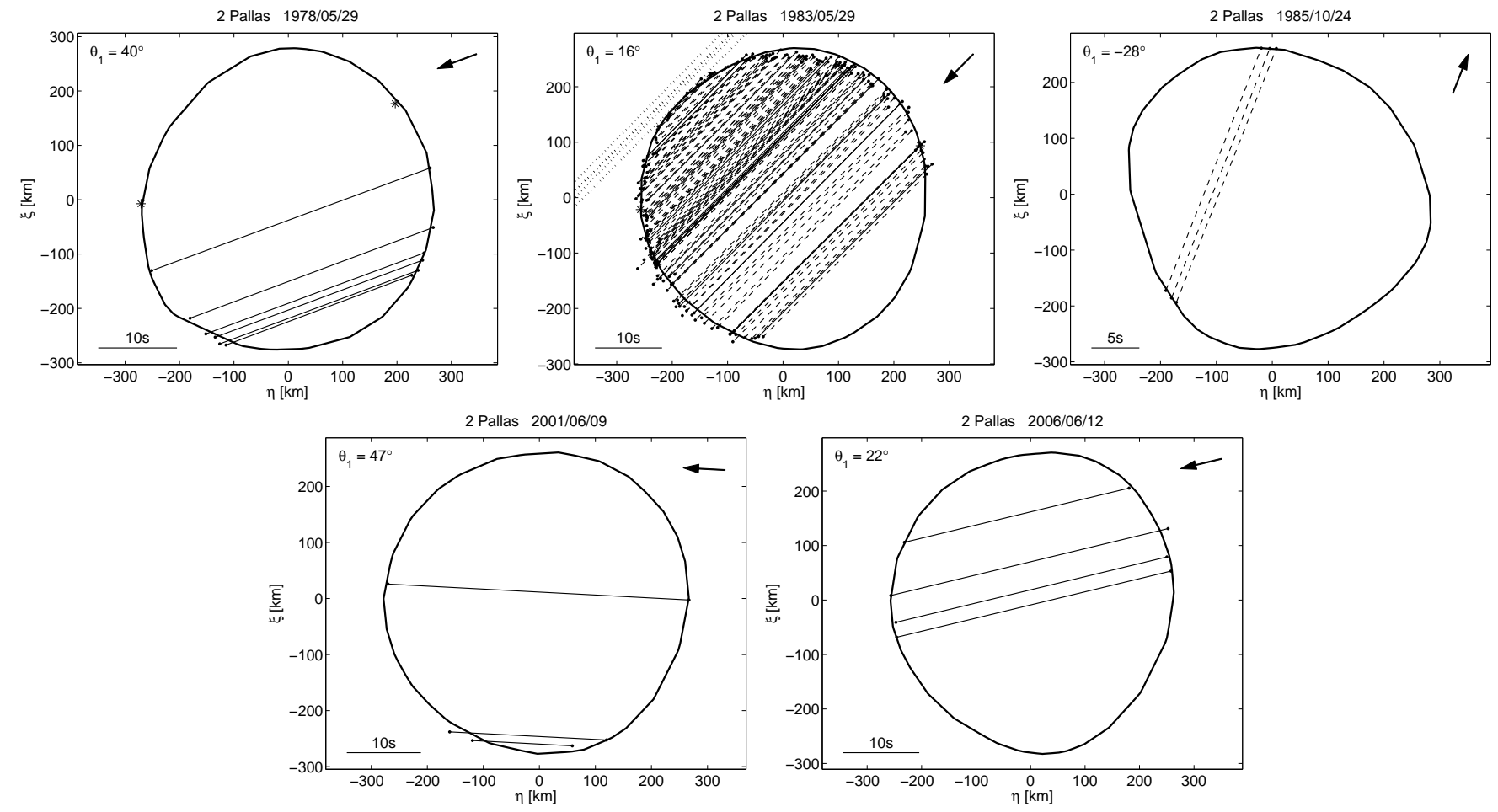

Figure 2: (2) Pallas
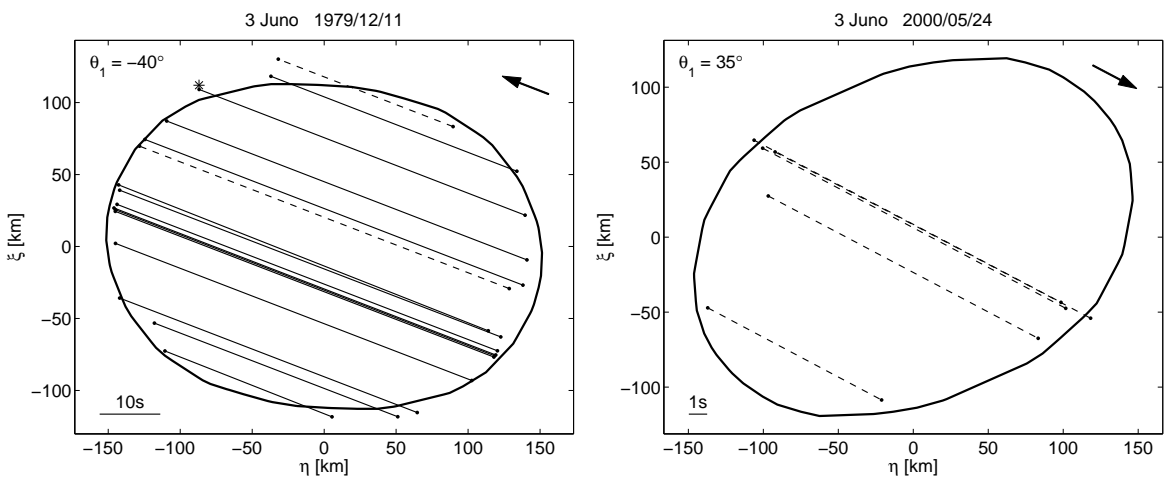

Figure 3: (3) Juno

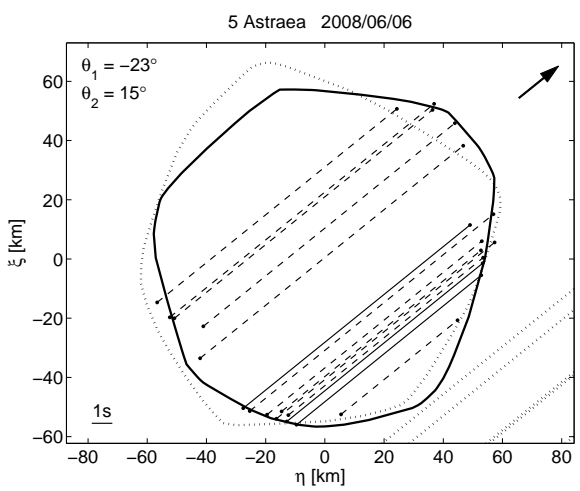

Figure 4: (5) Astraea. The solid contour corresponds to the model with the pole direction $\left(126^{\circ}, 40^{\circ}\right)$, the dotted one to the pole $\left(310^{\circ}, 44^{\circ}\right)$. 


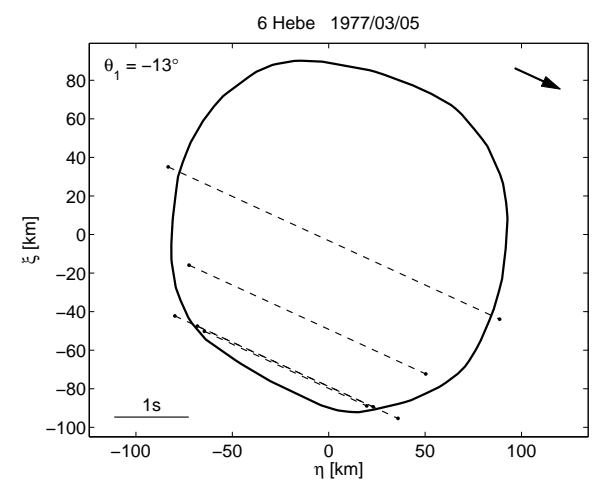

Figure 5: (6) Hebe.
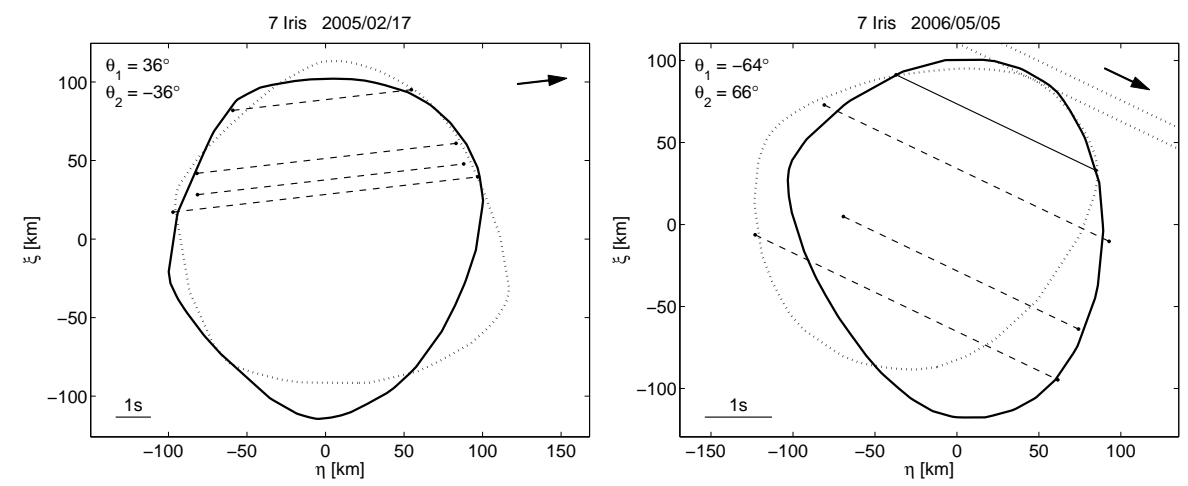

Figure 6: (7) Iris. The solid contour corresponds to the pole $\left(20^{\circ}, 14^{\circ}\right)$ and the dotted one to the pole $\left(199^{\circ},-2^{\circ}\right)$.

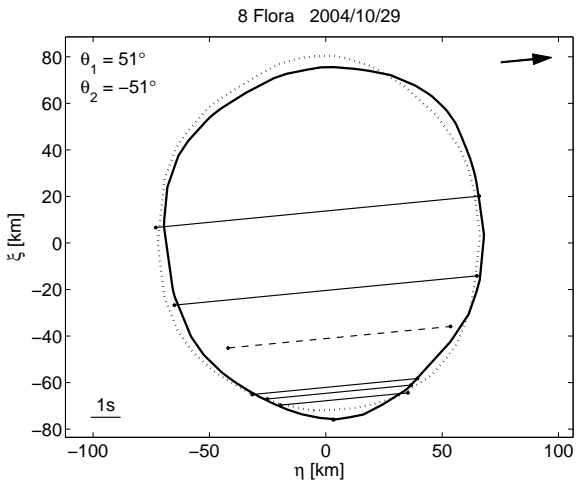

Figure 7: (8) Flora. The solid contour corresponds to the pole $\left(335^{\circ},-5^{\circ}\right)$, the dotted one to $\left(155^{\circ}, 6^{\circ}\right)$. 

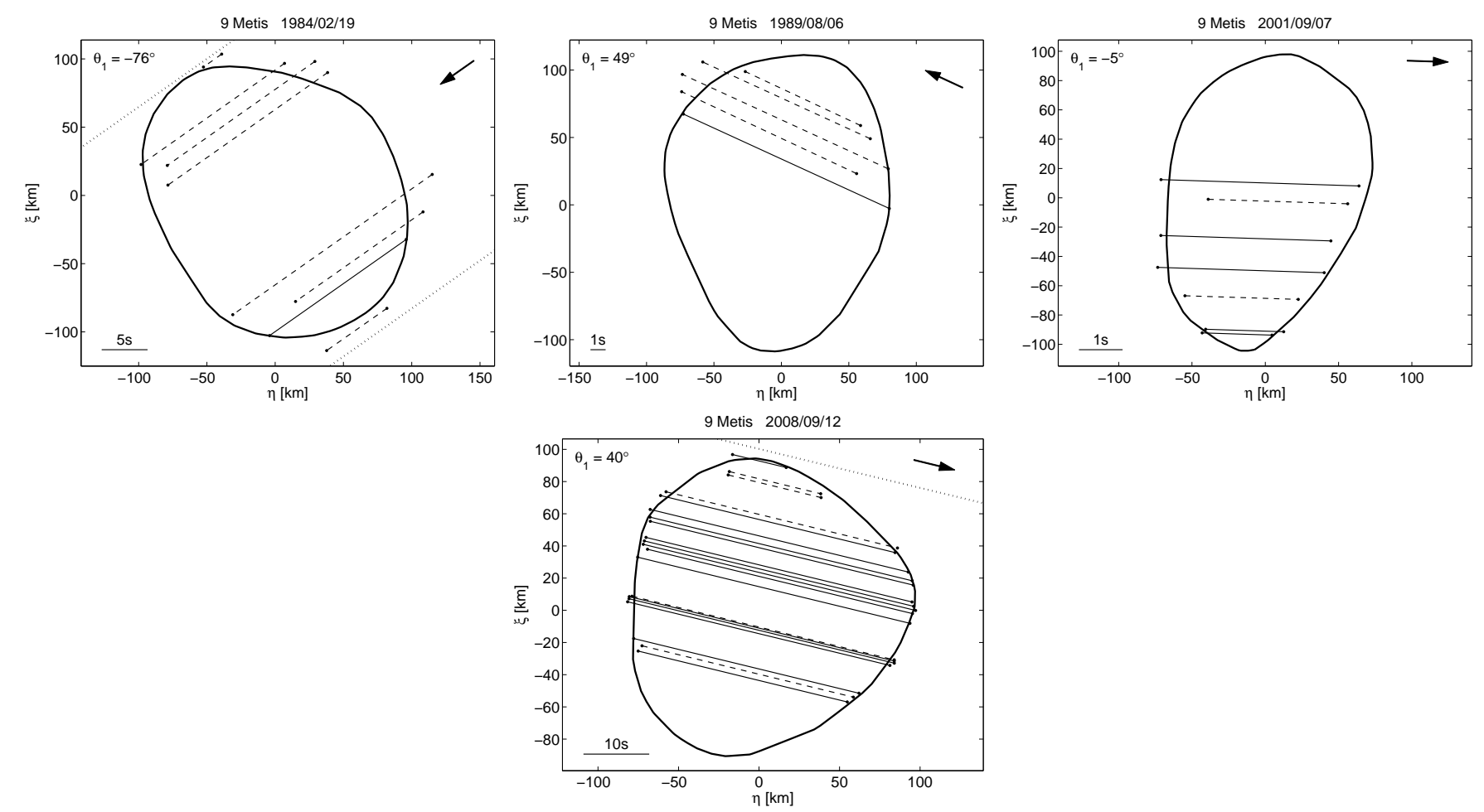

Figure 8: (9) Metis.

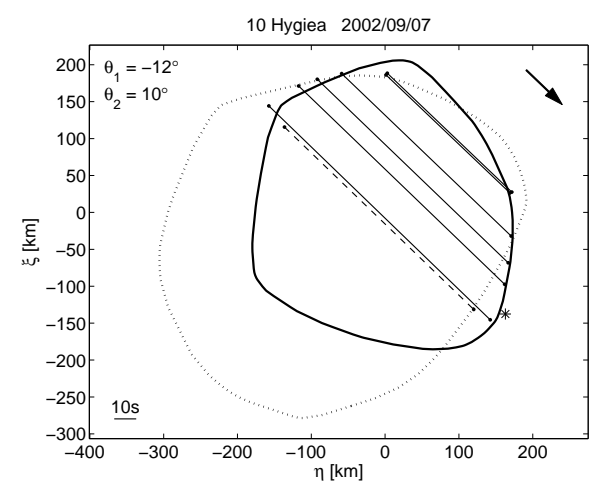

Figure 9: (10) Hygiea. The solid contour corresponds to the pole $\left(122^{\circ},-44^{\circ}\right)$, the dotted one to $\left(312^{\circ},-42^{\circ}\right)$.
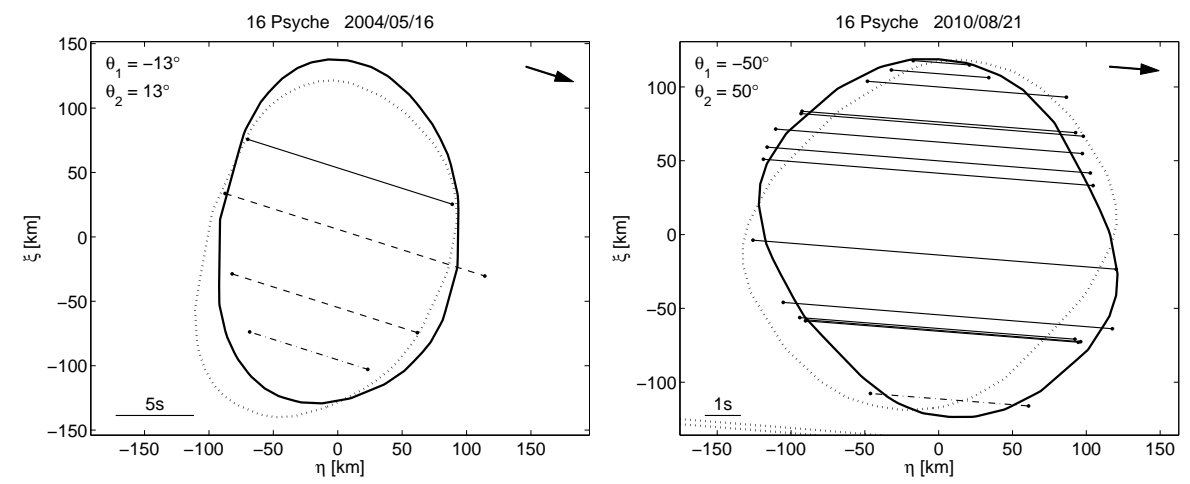

Figure 10: (16) Psyche. The solid contour corresponds to the pole $\left(33^{\circ},-7^{\circ}\right)$, the dotted one to $\left(213^{\circ}, 1^{\circ}\right)$. 


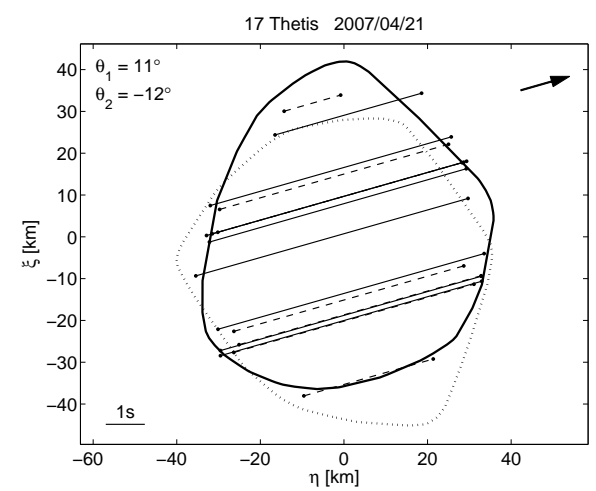

Figure 11: (17) Thetis. The solid contour corresponds to the pole $\left(236^{\circ}, 20^{\circ}\right)$, the dotted one to $\left(55^{\circ}, 10^{\circ}\right)$.

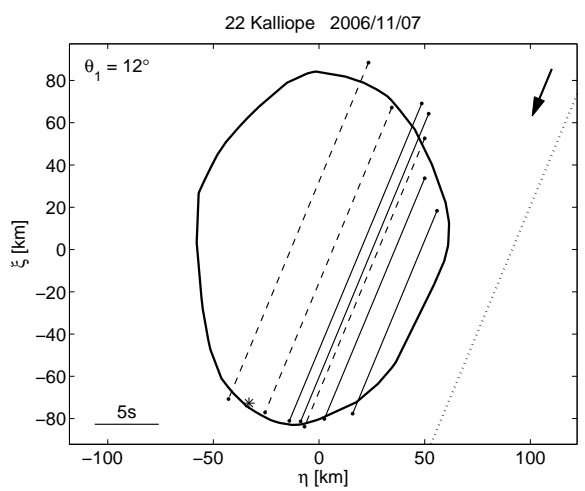

Figure 12: (22) Kalliope.

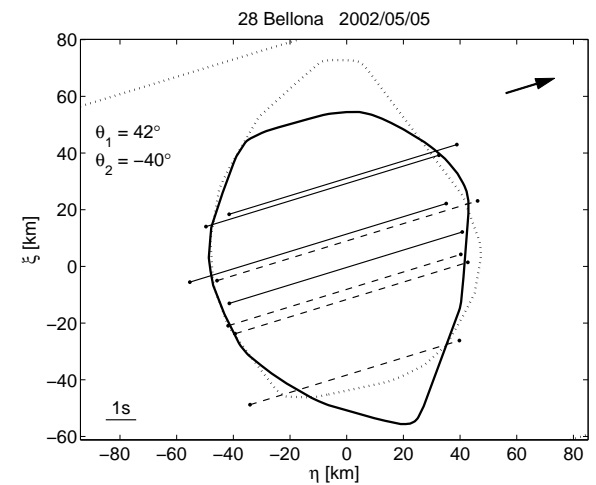

Figure 13: (28) Bellona. The solid contour corresponds to the pole $\left(282^{\circ}, 6^{\circ}\right)$, the dotted one to $\left(102^{\circ},-8^{\circ}\right)$. 


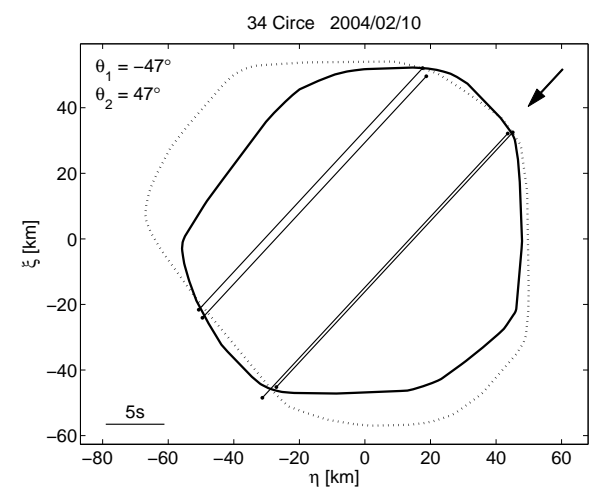

Figure 14: (34) Circe. The solid profile corresponds to the pole $\left(94^{\circ}, 35^{\circ}\right)$, the dotted one to $\left(275^{\circ}, 51^{\circ}\right)$.

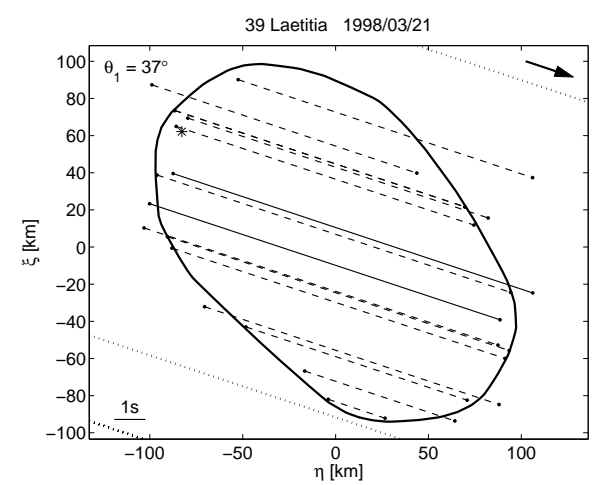

Figure 15: (39) Laetitia.

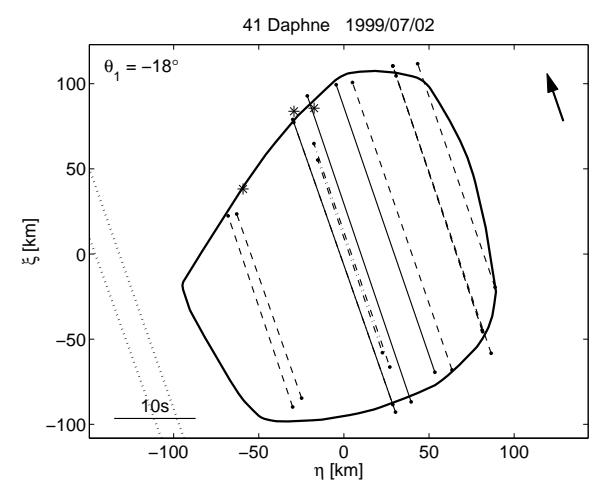

Figure 16: (41) Daphne. 

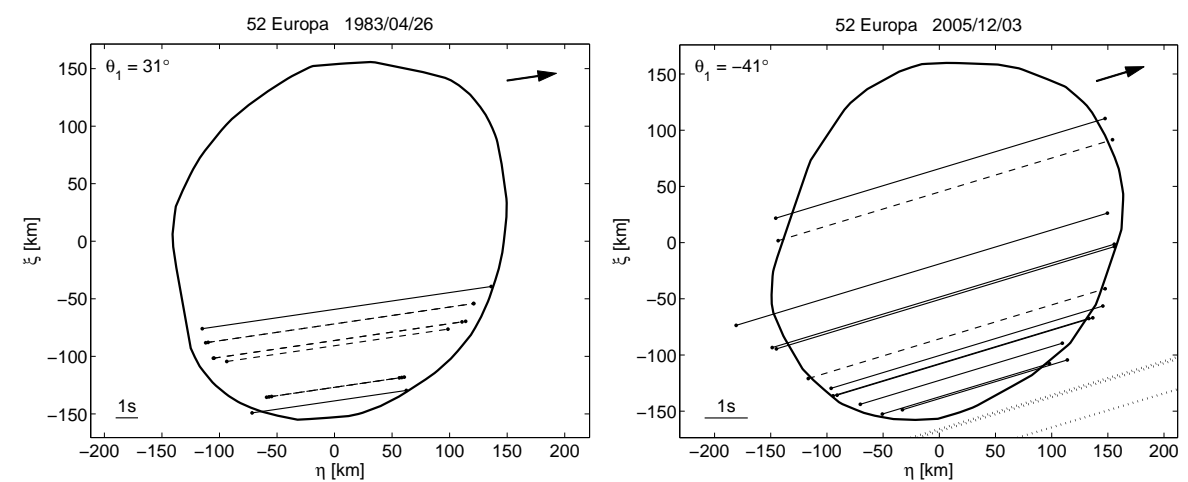

Figure 17: (52) Europa.

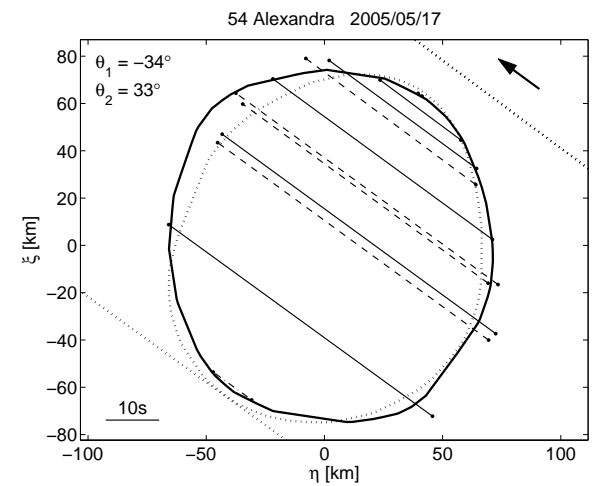

Figure 18: (54) Alexandra. The solid profile corresponds to the pole $\left(318^{\circ}, 23^{\circ}\right)$, the dotted one to $\left(156^{\circ}, 13^{\circ}\right)$.

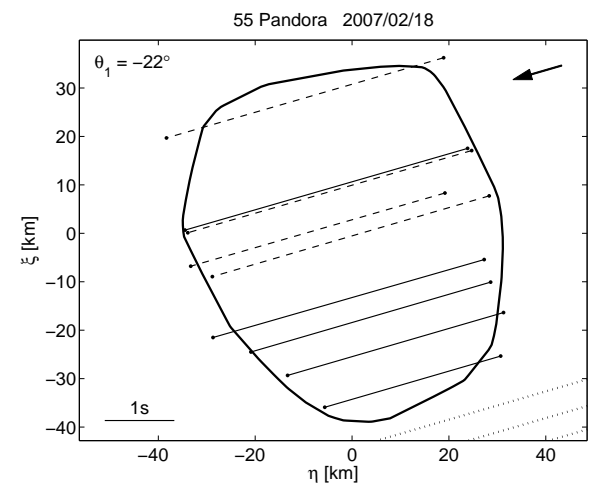

Figure 19: (55) Pandora. 


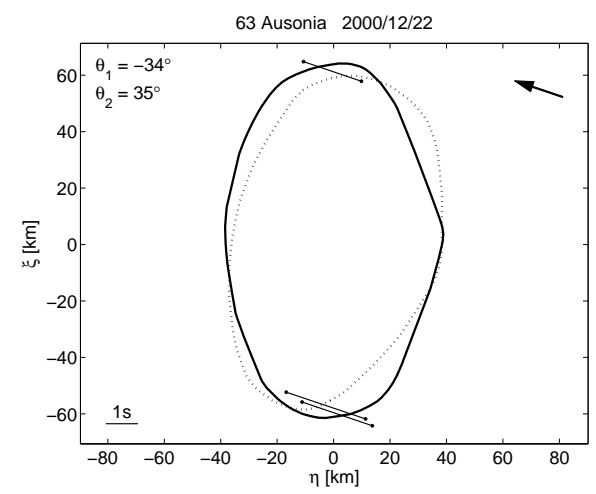

Figure 20: (63) Ausonia. The solid profile corresponds to the pole $\left(120^{\circ},-15^{\circ}\right)$, the dotted one to $\left(305^{\circ},-21^{\circ}\right)$.

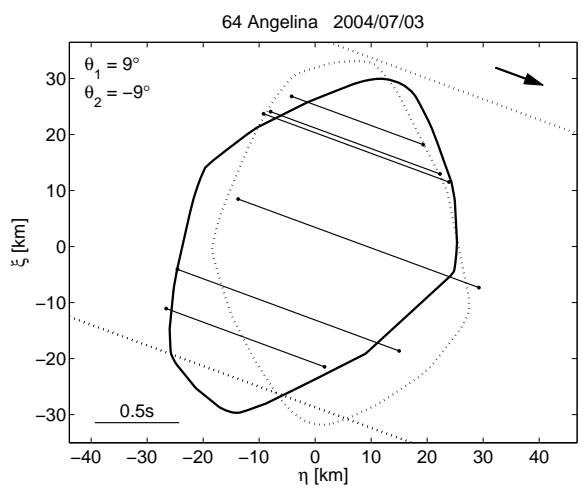

Figure 21: (64) Angelina. The solid profile corresponds to the pole $\left(137^{\circ}, 14^{\circ}\right)$, the dotted one to $\left(317^{\circ}, 17^{\circ}\right)$.

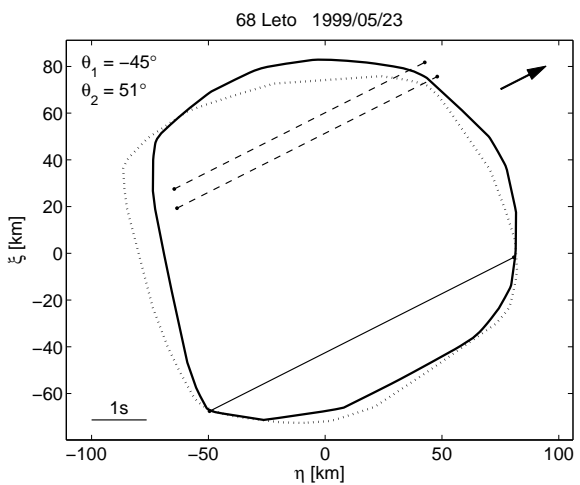

Figure 22: (68) Leto. The solid profile corresponds to the pole $\left(103^{\circ}, 43^{\circ}\right)$, the dotted one to $\left(209^{\circ}, 23^{\circ}\right)$. 


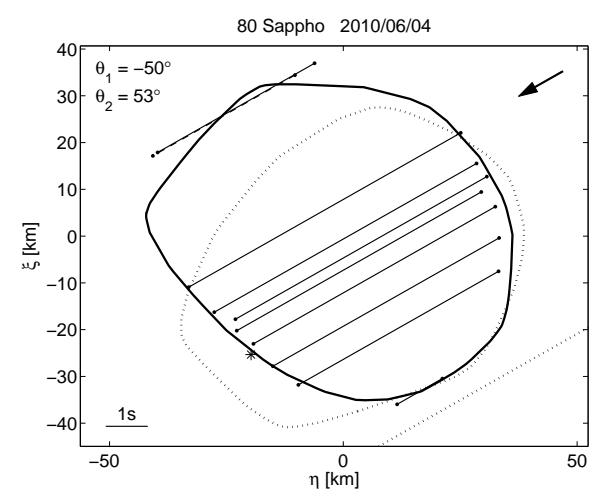

Figure 23: (80) Sappho. The solid profile corresponds to the pole $\left(194^{\circ},-26^{\circ}\right)$, the dotted one to $\left(6^{\circ},-16^{\circ}\right)$.
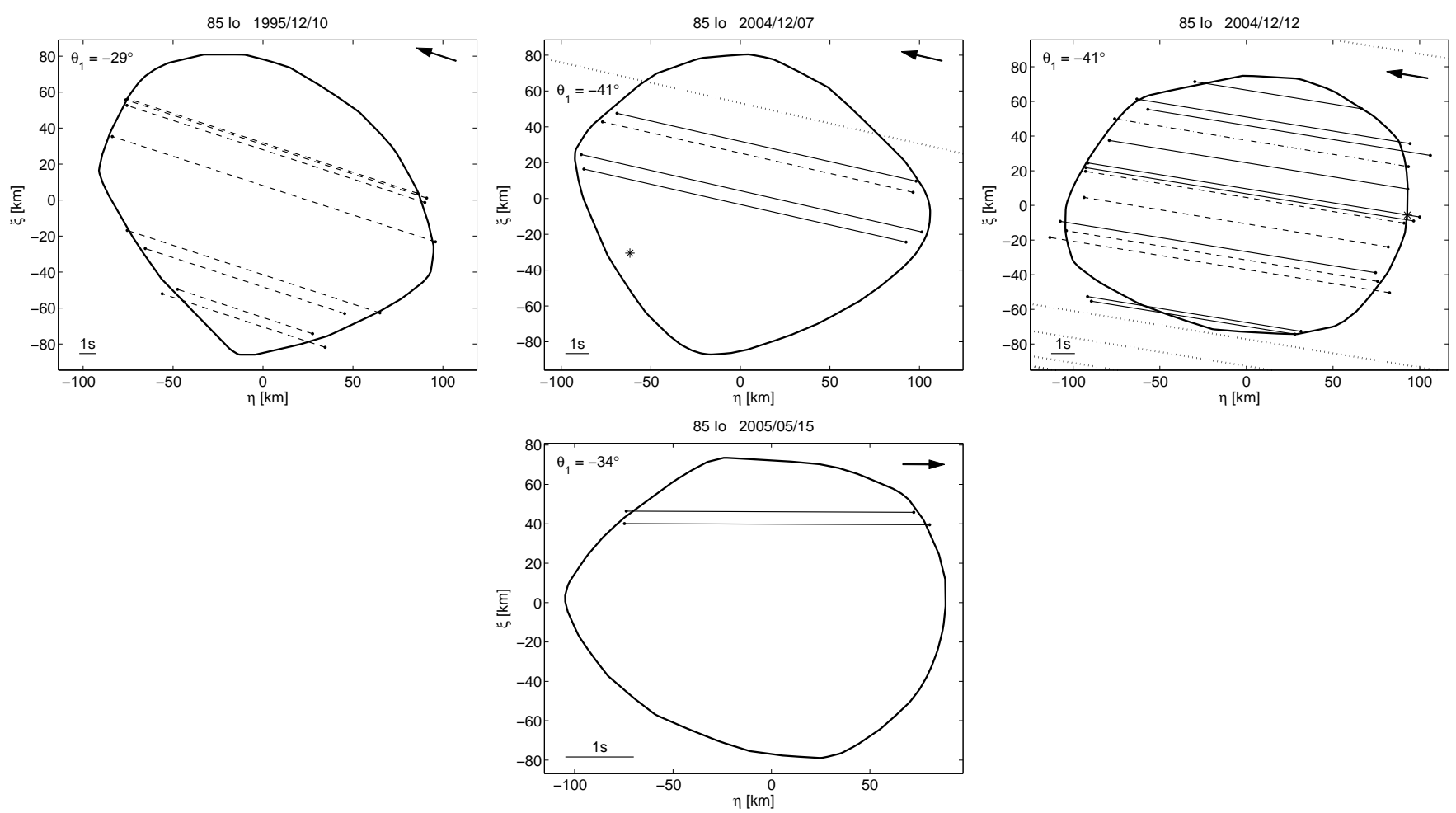

Figure 24: (85) Io.
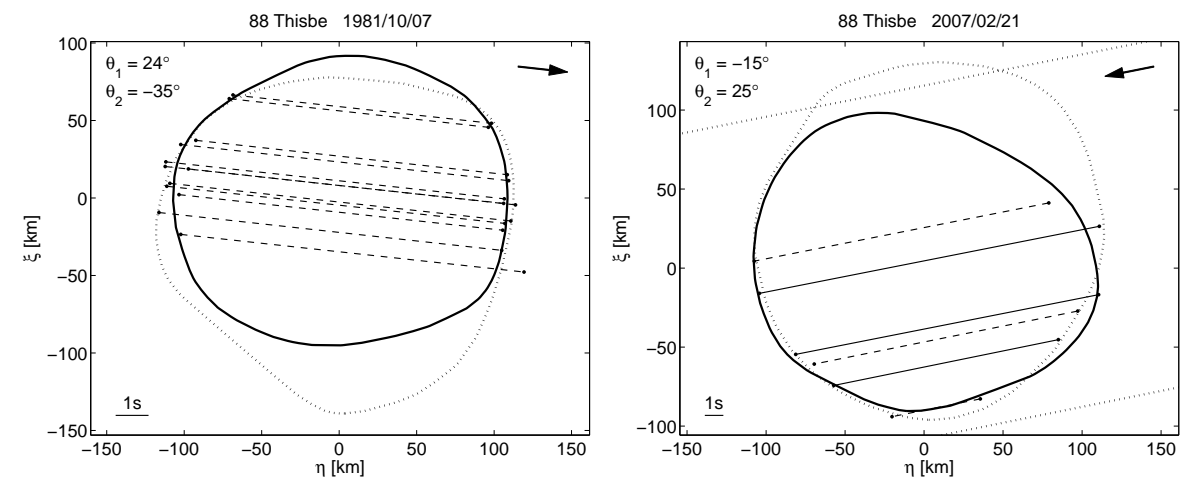

Figure 25: (88) Thisbe. The solid profile corresponds to the pole $\left(72^{\circ}, 60^{\circ}\right)$, the dotted one to $\left(247^{\circ}, 50^{\circ}\right)$. 

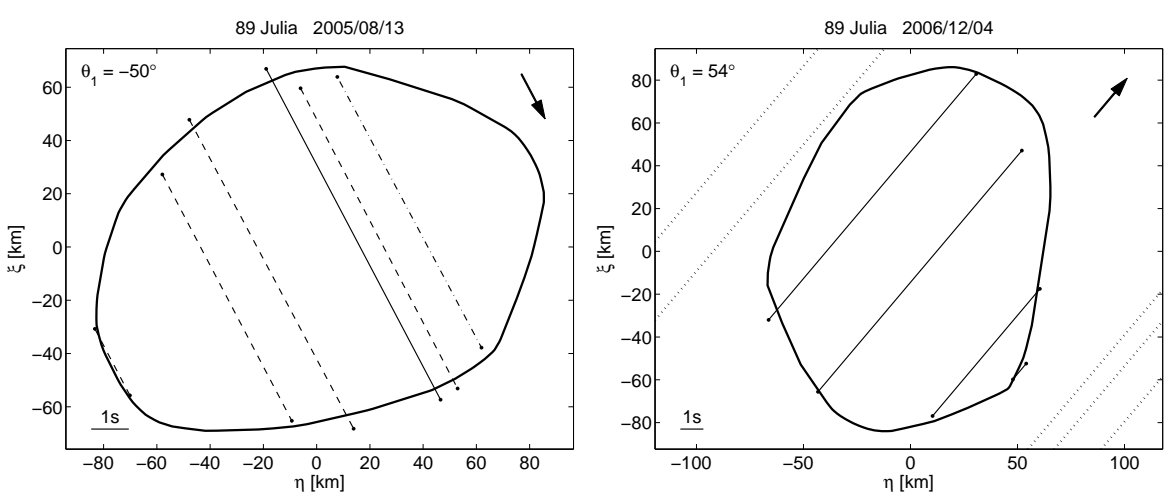

Figure 26: (89) Julia

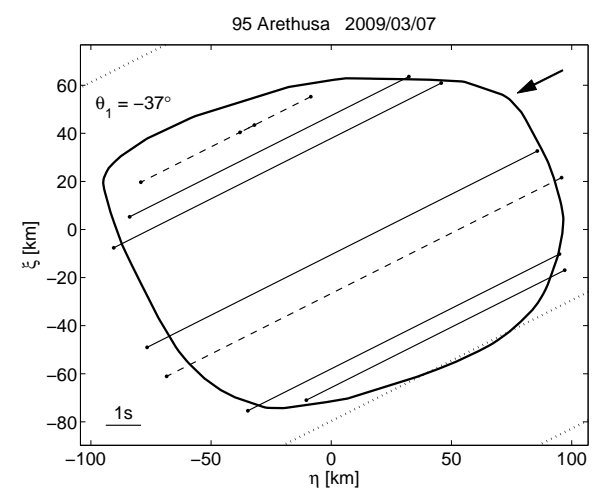

Figure 27: (95) Arethusa.

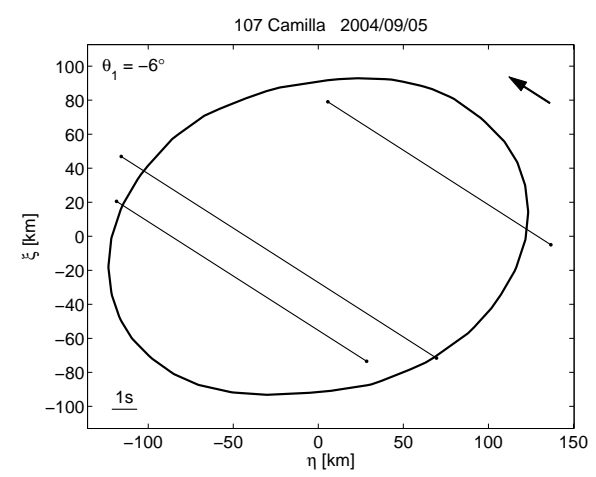

Figure 28: (107) Camilla. 

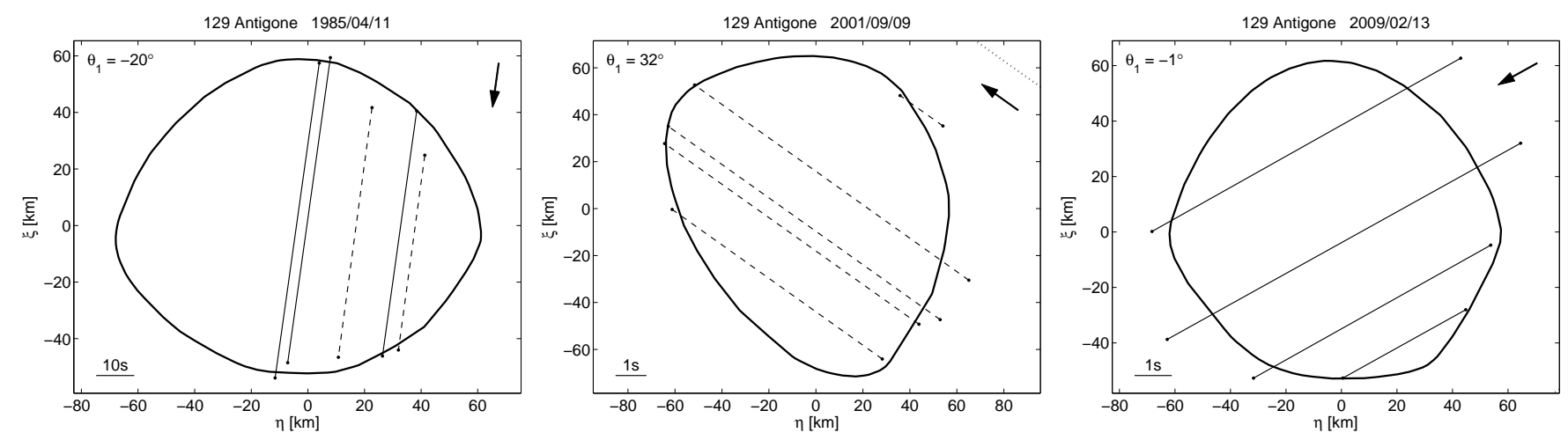

Figure 29: (129) Antigone.

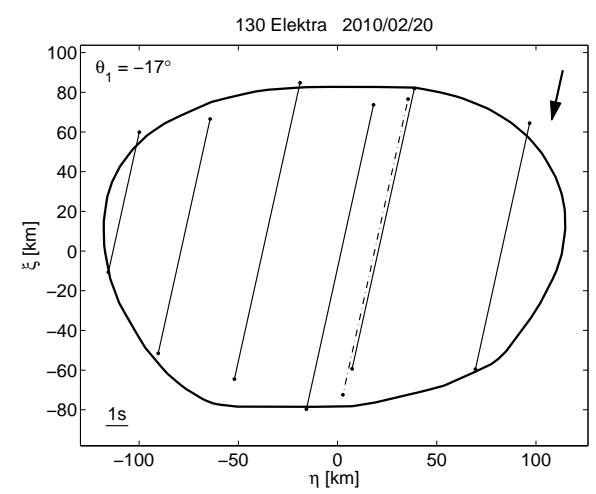

Figure 30: (130) Elektra.

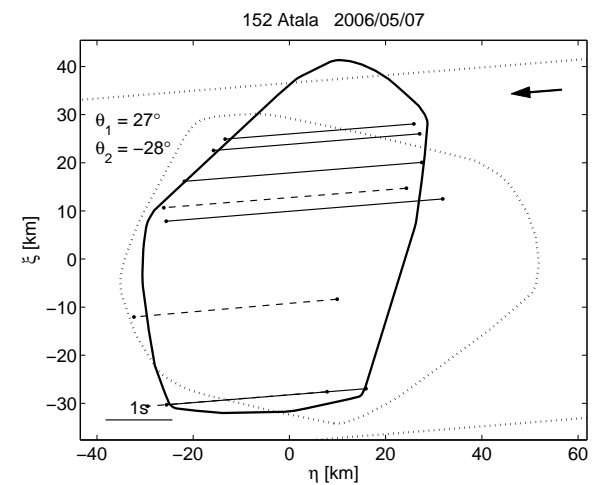

Figure 31: (152) Atala. The solid profile corresponds to the pole $\left(347^{\circ}, 47^{\circ}\right)$, the dotted one to $\left(199^{\circ}, 62^{\circ}\right)$. 


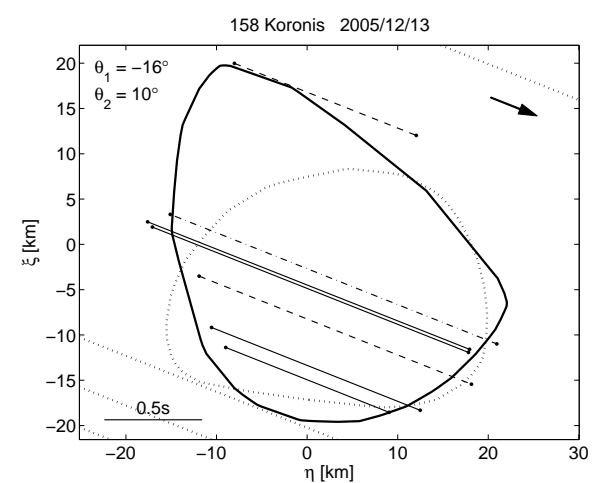

Figure 32: (158) Koronis. The solid profile corresponds to the pole $\left(30^{\circ},-64^{\circ}\right)$, the dotted one to $\left(225^{\circ},-70^{\circ}\right)$.

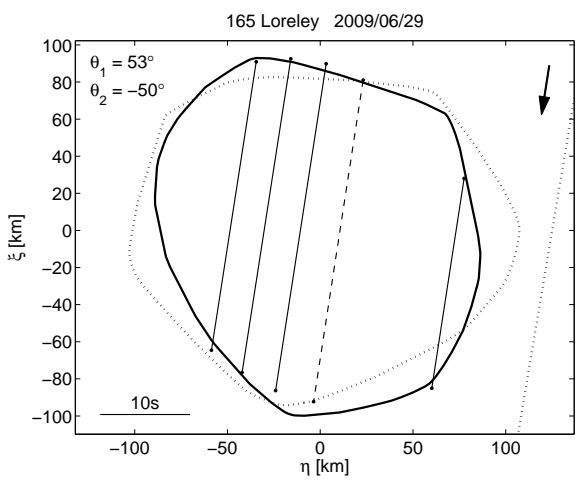

Figure 33: (165) Loreley. The solid profile corresponds to the pole $\left(174^{\circ}, 29^{\circ}\right)$, the dotted one to $\left(348^{\circ}, 42^{\circ}\right)$.

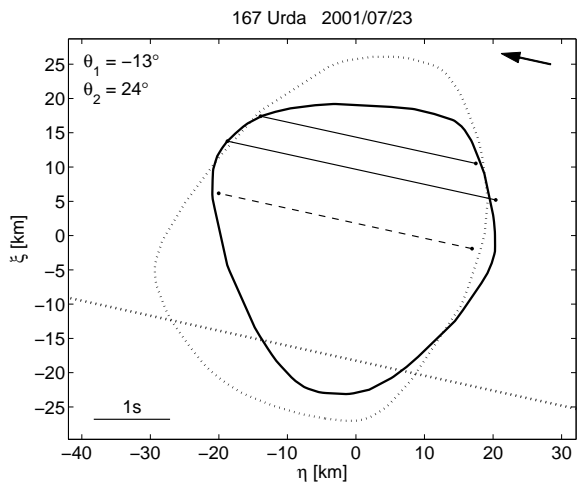

Figure 34: (167) Urda. The solid profile corresponds to the pole $\left(249^{\circ},-68^{\circ}\right)$, the dotted one to $\left(107^{\circ},-69^{\circ}\right)$. 


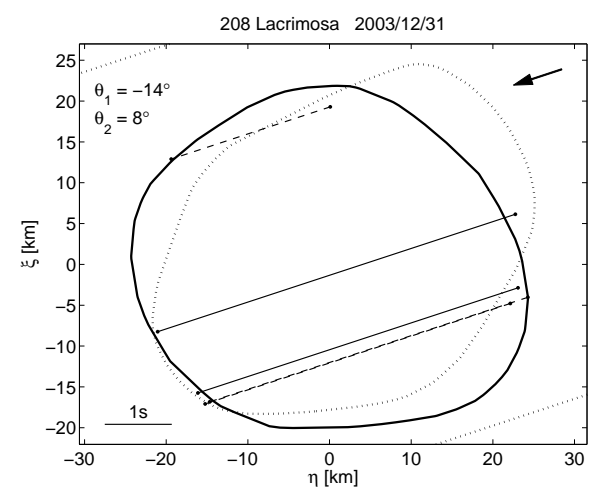

Figure 35: (208) Lacrimosa. The solid profile corresponds to the pole $\left(176^{\circ},-68^{\circ}\right)$, the dotted one to $\left(20^{\circ},-75^{\circ}\right)$.

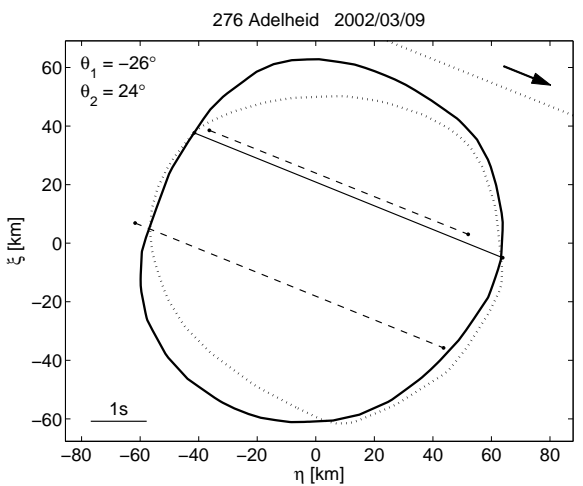

Figure 36: (278) Adelheid. The solid profile corresponds to the pole $\left(9^{\circ},-4^{\circ}\right)$, the dotted one to $\left(199^{\circ},-20^{\circ}\right)$.

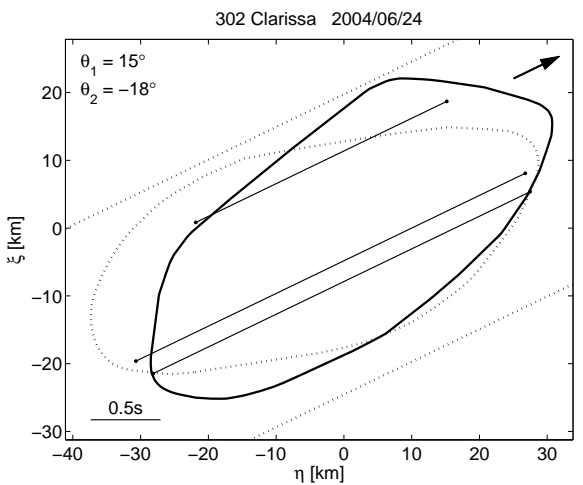

Figure 37: (302) Clarissa. The solid profile corresponds to the pole $\left(28^{\circ},-72^{\circ}\right)$, the dotted one to $\left(190^{\circ},-72^{\circ}\right)$. 


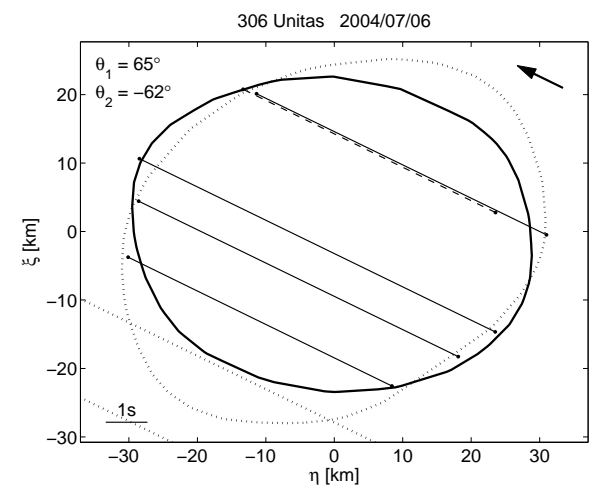

Figure 38: (306) Unitas. The solid profile corresponds to the pole $\left(79^{\circ},-35^{\circ}\right)$, the dotted one to $\left(253^{\circ},-17^{\circ}\right)$.
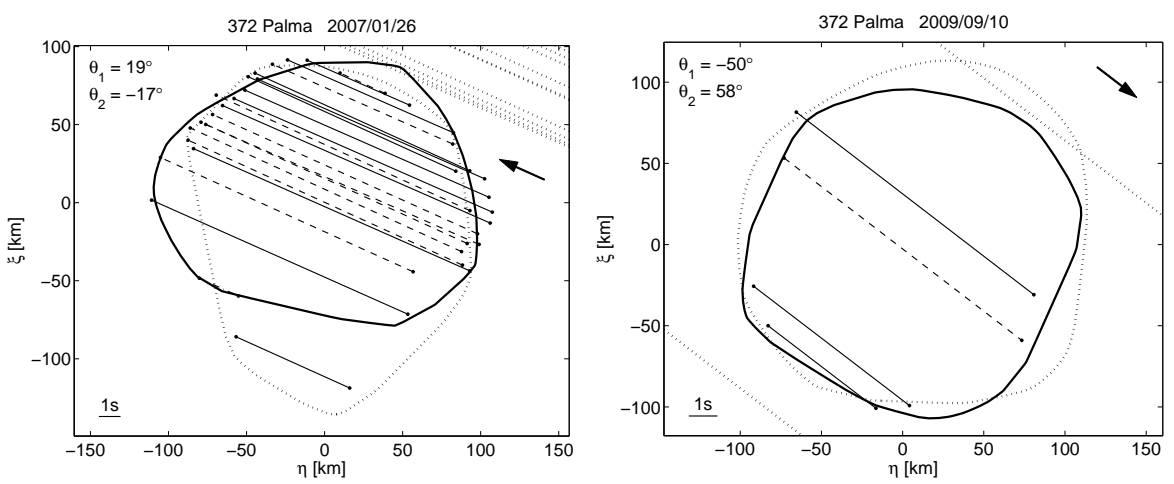

Figure 39: (372) Palma. The solid profile corresponds to the pole $\left(221^{\circ},-47^{\circ}\right)$, the dotted one to $\left(44^{\circ}, 17^{\circ}\right)$.
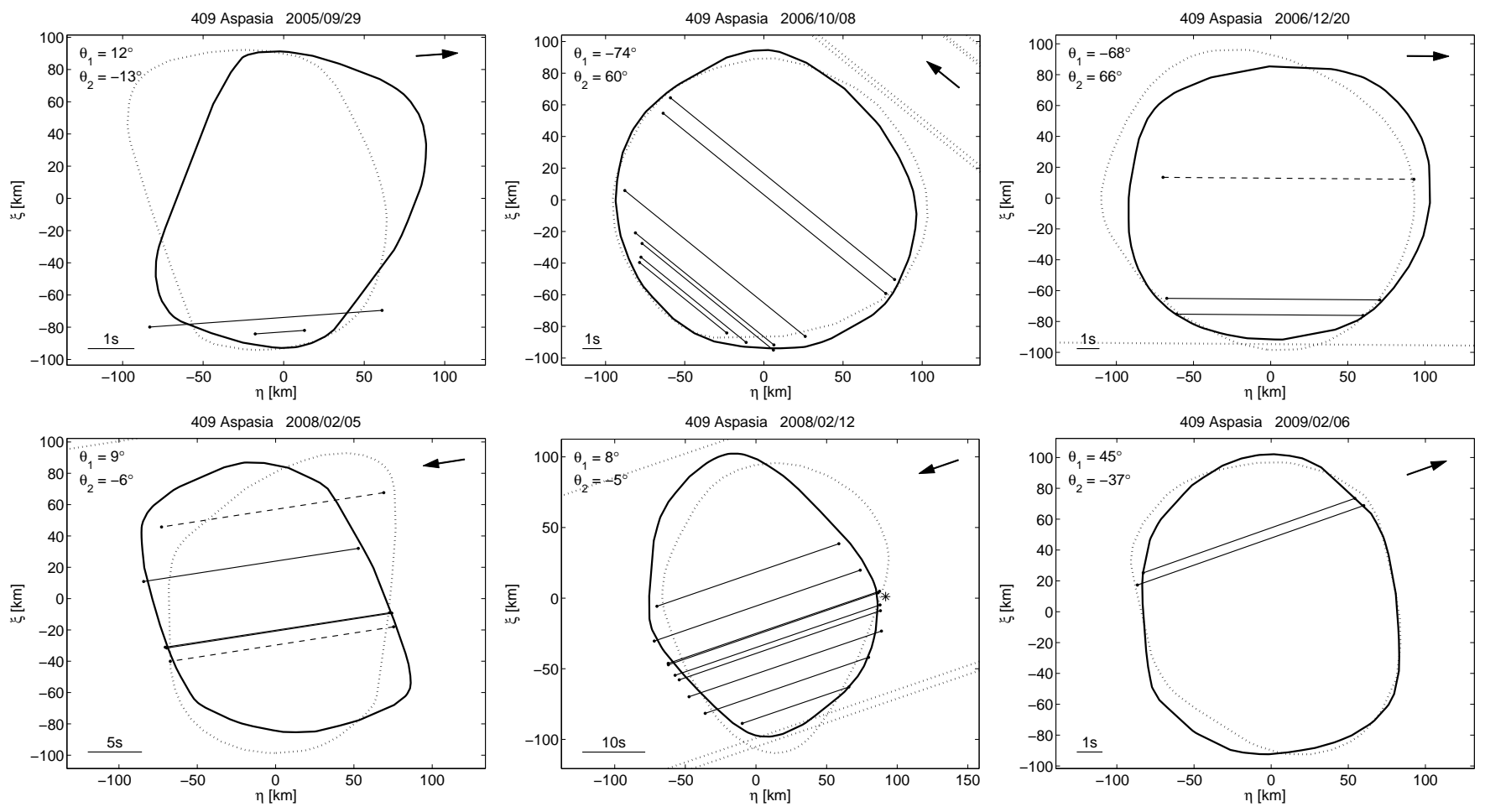

Figure 40: (409) Aspasia. The solid profile corresponds to the pole $\left(3^{\circ}, 30^{\circ}\right)$, the dotted one to $\left(177^{\circ}, 15^{\circ}\right)$. 


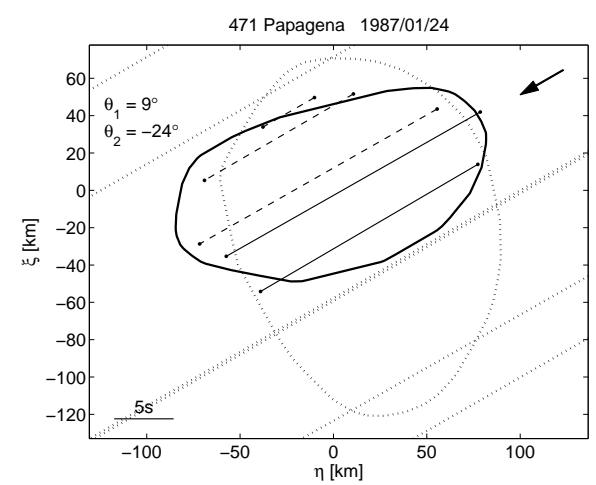

Figure 41: (471) Papagena. The solid profile corresponds to the pole $\left(223^{\circ}, 67^{\circ}\right)$, the dotted one to $\left(22^{\circ}, 18^{\circ}\right)$.
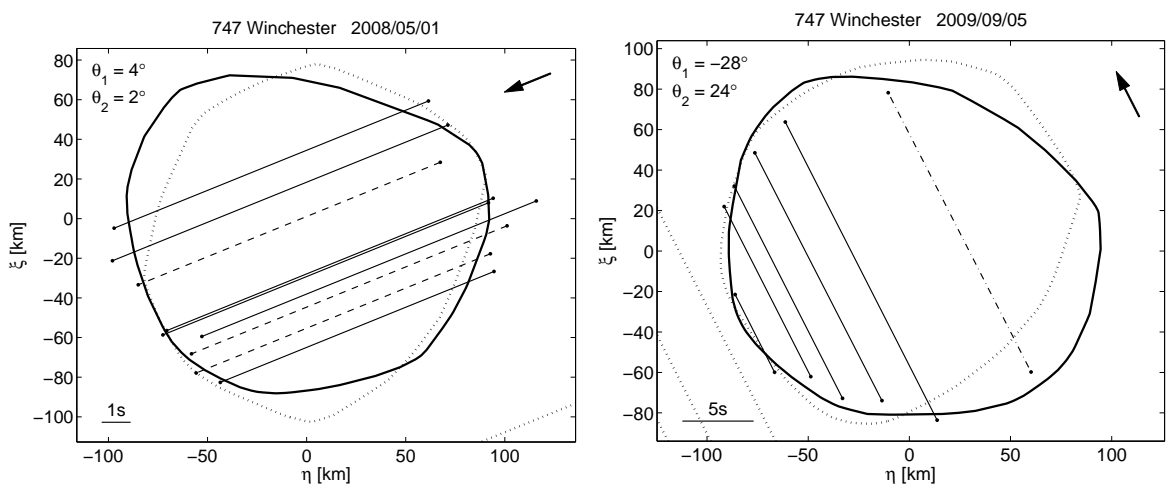

Figure 42: (747) Winchester. The solid profile corresponds to the pole $\left(304^{\circ},-60^{\circ}\right)$, the dotted one to $\left(172^{\circ},-36^{\circ}\right)$.

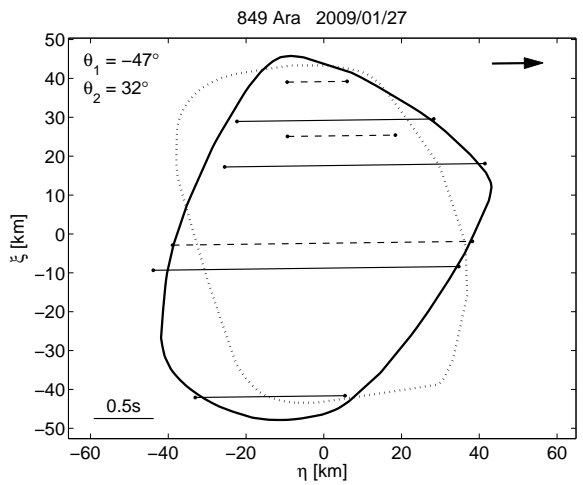

Figure 43: (849) Ara. The solid profile corresponds to the pole $\left(223^{\circ},-40^{\circ}\right)$, the dotted one to $\left(10^{\circ},-25^{\circ}\right)$. 

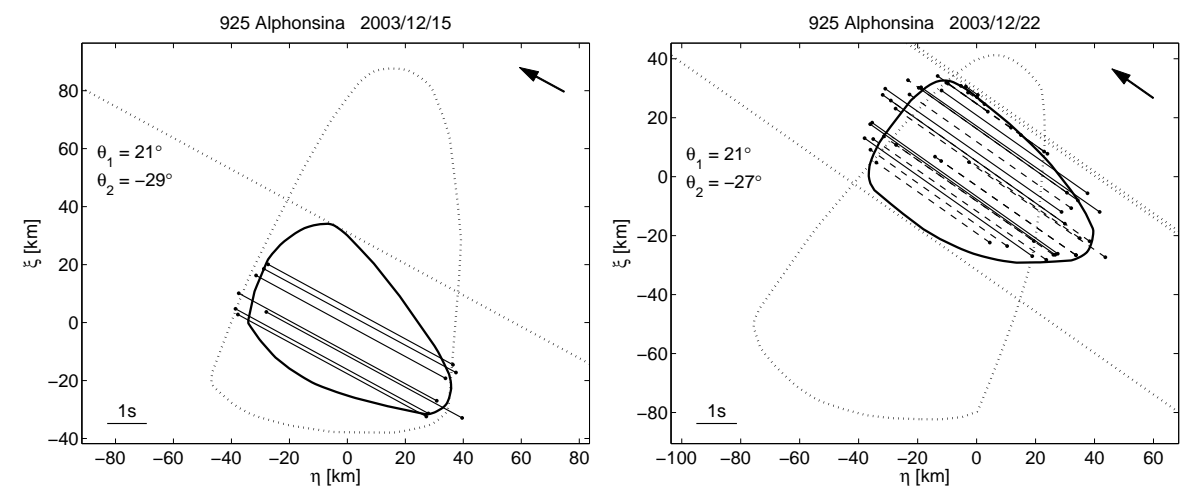

Figure 44: (925) Alphonsina. The solid profile corresponds to the pole $\left(294^{\circ}, 41^{\circ}\right)$, the dotted one to $\left(148^{\circ}, 25^{\circ}\right)$.

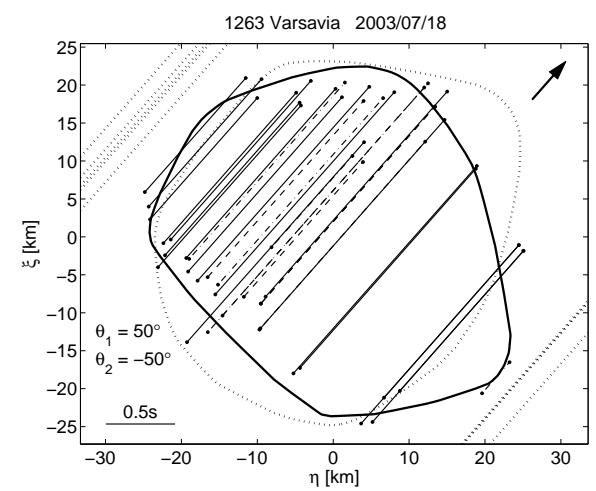

Figure 45: (1263) Varsavia. The solid profile corresponds to the pole $\left(341^{\circ},-14^{\circ}\right)$, the dotted one to $\left(172^{\circ},-1^{\circ}\right)$. 